\title{
The importance of spawning behavior in understanding the vulnerability of exploited marine fishes in the U.S. Gulf of Mexico
}

\author{
Christopher R. Biggs ${ }^{1}$, William D Heyman ${ }^{2}$, Nicholas A Farmer ${ }^{3}$, Shin'ichi Kobara ${ }^{4}$, Derek G Bolser ${ }^{1}$, Jan \\ Robinson $^{5}$, Susan K Lowerre-Barbieri ${ }^{6}$, Brad E Erisman ${ }^{\text {Corresp. 1, } 7}$ \\ ${ }^{1}$ Marine Science Institute, The University of Texas at Austin, Port Aransas, Texas, United States \\ 2 LGL Ecological Research Associates, Inc., Bryan, Texas, United States \\ ${ }^{3}$ Southeast Regional Office, NOAA National Marine Fisheries Service, St. Petersburg, Florida, United States \\ 4 Department of Oceanography, Texas A\&M University, College Station, Texas, United States \\ 5 Australian Research Council (ARC) Centre of Excellence for Coral Reef Studies, James Cook University, Townsville, Queensland, Australia \\ 6 Fisheries and Aquatic Science Program, School of Forest Resources and Conservation, University of Florida, Gainesville, Florida, United States \\ 7 Fisheries Resources Division, Southwest Fisheries Science Center, National Marine Fisheries Service, National Oceanic and Atmospheric Administration, \\ La Jolla, California, United States \\ Corresponding Author: Brad E Erisman \\ Email address: berisman@utexas.edu
}

The vulnerability of a fish stock to becoming overfished is dependent upon biological traits that influence productivity and external factors that determine susceptibility or exposure to fishing effort. While a suite of life history traits are traditionally incorporated into management efforts due to their direct association with vulnerability to overfishing, spawning behavioral traits are seldom considered. We synthesized the existing biological and fisheries information of 28 fish stocks in the U.S. Gulf of Mexico to investigate relationships between life history traits, spawning behavioral traits, management regulations, and vulnerability to fishing during the spawning season. Our results showed that spawning behavioral traits were not correlated with life history traits but improved identification of species that have been historically overfished. Species varied widely in their intrinsic vulnerability to fishing during spawning in association with a broad range of behavioral strategies. Extrinsic vulnerability was high for nearly all species due to exposure to fishing during the spawning season and few management measures in place to protect spawning fish. Similarly, several species with the highest vulnerability scores were historically overfished in association with spawning aggregations. The most vulnerable species included several stocks that have not been assessed and should be prioritized for further research and monitoring. Collectively, the results of this study illustrate that spawning behavior is a distinct aspect of fish ecology that is important to consider for predictions of vulnerability and resilience to fisheries exploitation. 


\section{The importance of spawning behavior in}

2 understanding the vulnerability of exploited marine

3 fishes in the U.S. Gulf of Mexico

Christopher R. Biggs ${ }^{1}$, William D. Heyman², Nicholas A. Farmer ${ }^{3}$, Shinichi Kobara ${ }^{4}$, Derek G.

${ }^{1}$ Department of Marine Science, University of Texas at Austin, Port Aransas, TX, USA

$11{ }^{2}$ LGL Ecological Research Associates, Inc., Bryan, TX, USA

$12{ }^{3}$ NOAA National Marine Fisheries Service, Southeast Regional Office, St. Petersburg, FL, USA

$13{ }^{4}$ Department of Oceanography, Texas A\&M University, College Station, TX, USA

$14{ }^{5}$ Australian Research Council (ARC) Centre of Excellence for Coral Reef Studies, James Cook

15 University, Townsville, QLD, Australia

$16{ }^{6}$ Fisheries and Aquatic Science Program, School of Forest Resources and Conservation,

17 University of Florida, Gainesville, FL, USA

18 "NOAA National Marine Fisheries Service, Southwest Fisheries Science Center, La Jolla, CA,

19 USA (present address)

21 Corresponding Author:

22 Brad E. Erisman ${ }^{1,7}$

23 NOAA National Marine Fisheries Service, Southwest Fisheries Science Center, La Jolla, CA, 24 USA

25 Email address: brad.erisman@noaa.gov 


\section{Abstract}

28 The vulnerability of a fish stock to becoming overfished is dependent upon biological traits that influence productivity and external factors that determine susceptibility or exposure to fishing effort. While a suite of life history traits are traditionally incorporated into management efforts due to their direct association with vulnerability to overfishing, spawning behavioral traits are seldom considered. We synthesized the existing biological and fisheries information of 28 fish stocks in the U.S. Gulf of Mexico to investigate relationships between life history traits, spawning behavioral traits, management regulations, and vulnerability to fishing during the spawning season. Our results showed that spawning behavioral traits were not correlated with life history traits but improved identification of species that have been historically overfished. Species varied widely in their intrinsic vulnerability to fishing during spawning in association with a broad range of behavioral strategies. Extrinsic vulnerability was high for nearly all species due to exposure to fishing during the spawning season and few management measures in place to protect spawning fish. Similarly, several species with the highest vulnerability scores were historically overfished in association with spawning aggregations. The most vulnerable species included several stocks that have not been assessed and should be prioritized for further research and monitoring. Collectively, the results of this study illustrate that spawning behavior is a

44 distinct aspect of fish ecology that is important to consider for predictions of vulnerability and 45 resilience to fisheries exploitation. 
51

52

53

54

55

56

57

58

59

60

61

62

63

64

65

66

67

68

69

70

71

72

73

74

75

76

77

78

79

80

81

82

83

84

85

86

87

88

89

90

91

92

93

94

95

96

\section{Introduction}

The vulnerability of a stock, population, or species of marine fish to become overfished or experience overfishing is dependent upon both intrinsic aspects of its evolutionary history, ecology, and population biology as well as extrinsic factors related to the fishery and its management that determine the level of exposure to fishing pressure (Jennings et al. 1998; Dulvy et al. 2004; Patrick et al. 2010). Intrinsic vulnerability is a function of various life history traits (e.g., growth rate or longevity) and behavioral traits (e.g., spatiotemporal spawning patterns) that influence stock productivity and resilience: the capacity of a fish population to recover once it becomes depleted (Adams 1980; Reynolds et al. 2001; Stobutzki et al. 2001). Conversely, extrinsic vulnerability factors are linked to the dynamics of the fishery (e.g., fishing effort or catch efficiency), the effectiveness of management policies, and governance structure that combine to determine stock susceptibility and the potential for the fishery to negatively impact stock condition (Cinner et al. 2009; Hobday et al. 2011; Leslie et al. 2015). In situations where insufficient information exists to perform quantitative assessments of biomass or modelling of population dynamics, intrinsic and extrinsic attributes associated with productivity of the stock and exposure to fishing pressure can be used to estimate the overall vulnerability of a stock relative to others in the same region (Frisk et al. 2005; Patrick et al. 2010; Hobday et al. 2011). Furthermore, vulnerability analyses and conservation evaluations have been useful in identifying stocks that should be prioritized for additional research and monitoring (Morato et al. 2006; Davies and Baum 2012; Mamauag et al. 2013).

A suite of life history traits is associated with a high intrinsic vulnerability to becoming overfished. Fish species that are slow growing, long-lived, late to mature, and experience low natural mortality are consistently linked to reduced resilience and increased risk of population collapse in response to fishing (Jennings et al. 1998; Musick 1999; King and McFarlane 2003; Winemiller 2005). Moreover, certain life history traits correlate with each other as intrinsic indicators of vulnerability or compensatory capacity (Dulvy et al. 2004; Kindsvater et al. 2016). For example, fish with slow growth rates tend to have low natural mortalities and late onset of sexual maturity, although there are exceptions (see Coulson 2019). Life history traits (e.g., growth, reproduction, and death rates) are integral to data-limited stock assessments, but they are also used within data-rich stock assessments (e.g., length or age-structured models) when sufficient data are available (Hilborn and Walters 1992; Methot and Wetzel 2013). Likewise, most vulnerability assessments are designed to account for vulnerability associated with life history traits. However, certain types of spawning behaviors and reproductive patterns are also associated with a high intrinsic vulnerability to fishing but are not typically incorporated into assessment frameworks and thus do not account for this source of vulnerability.

Spawning behavior is associated with productivity (Cheung et al. 2005) and resilience (Lowerre-Barbieri et al. 2017) in marine fishes such that the spatial and temporal components of spawning may affect the relationship between stocks and recruitment, affecting how a species responds to fishing pressure (Maunder and Deriso 2013; Donahue et al. 2015; Erisman et al. 2017a). For instance, the number of spawning sites and number of spawning opportunities are positively correlated with increased reproductive resilience (Erisman et al. 2011; LowerreBarbieri et al. 2015). The duration of the spawning season is inversely related to vulnerability, in which species with predictable but brief spawning periods are associated with the most rapid and severe population declines compared to those that spawn year-round or over protracted seasons (Mullon et al. 2005; Claro et al. 2009; Sadovy De Mitcheson and Erisman 2012). Large changes 
97 in fish densities or relative abundance in association with spawning are directly linked to marked 98 increases in catchability, which also increases susceptibility and overall vulnerability to fishing 99 (Wilberg et al. 2010; Erisman et al. 2011, 2014; Robinson and Samoilys 2013; Robinson 2015).

100 Catchability is an important factor in fisheries assessments (Hilborn and Walters 1992; Arreguin-

101 Sanchez 1996) but can be difficult to estimate, as it is affected by a combination of extrinsic

102 factors (fishery and management related) and intrinsic factors such as aggregating behavior and

103 changes in relative abundance (Skjold et al. 1996; Solmundsson et al. 2003; Erisman et al. 2011).

The continuum of adult behavioral dynamics that collectively determine the spatial and temporal characteristics of spawning can be described based on the degree of aggregating behavior, the duration of spawning season, and the change in relative abundance of fish during spawning (Claydon et al. 2014; Lowerre-Barbieri et al. 2017; Erisman et al. 2017b). On one end of the spectrum are transient aggregations, which include individuals that have migrated from within a large catchment area to congregate in high densities at very specific locations during predictable periods (Domeier 2012). On the other end of the spectrum are species that do not aggregate to spawn or exhibit simple migratory behavior, in which an entire group or population moves from a foraging ground to a spawning area without a change in relative abundance (Domeier 2012). Also, within the spectrum of spawning behaviors are resident aggregations that include fishes that form small spawning aggregations of a few to a few dozen individuals, which often occur throughout the year and draw from small catchment areas. Lastly, some populations or species of fish are mixed spawners that employ a combination of resident and transient spawning behaviors in different areas and times (Lowerre-Barbieri et al. 2009; Tinhan et al. 2014).

Understanding interspecific variations in reproductive behaviors including reproductive migration patterns, changes in relative abundance, and the timing, duration, and spatial distribution of spawning activities may help scientists and managers better understand the intrinsic vulnerability of a species to fishing in relation to spawning and manage for resilience. Yet, the reproductive potential of a stock is typically measured based on spawning stock biomass or total egg production (i.e., fecundity), rather than traits affecting reproductive resilience (Lowerre-Barbieri et al., 2017), including spatiotemporal behavioral traits, although spawning season duration is used to estimate annual fecundity in indeterminate species (Cooper et al. 2013; Maunder and Deriso 2013; Ganias et al. 2014). While spawning behavior traits have been considered in some vulnerability analyses (Cheung et al. 2005; Erisman et al. 2014; Robinson and Samoilys 2013; Robinson et al. 2015), this aspect of fish ecology remains poorly studied, under-utilized for assessing stock health, and rarely emphasized in management frameworks (e.g. Erisman et al. 2011; Sadovy De Mitcheson and Erisman 2012; Cheung et al. 2013).

Given the influence life history and spawning behavioral traits have on vulnerability, it is important to consider whether these traits are correlated and how well they explain vulnerability to fishing during spawning and exploitation status. If life history and spawning behavior traits are not correlated, then for situations in which spawning behavior improves predictions of vulnerability, increased research efforts to understand spawning behaviors would help identify vulnerable species that may otherwise be overlooked and identify areas where targeted protection of spawning fish may be needed to maintain sustainable harvest levels or rebuild overfished stocks (Grüss and Robinson 2014; Grüss et al. 2018). Studies that have examined the relationship between life history traits and spawning behavior were conducted in tropical regions and did not focus explicitly on exploited species (e.g. Choat 2012; Nemeth 2012). Therefore, uncovering this relationship and identifying species whose vulnerability to fishing is not explained by life history 
143 traits alone would assist managers in prioritizing research, monitoring, and assessment efforts 144 accordingly.

The U.S. Gulf of Mexico (GOM) presents an ideal opportunity to answer important questions about relationships between life history traits, reproductive behavior, and the vulnerability of exploited marine fishes during the spawning season. The GOM is a highly productive system that supports a diverse set of taxa (i.e., numerous families) of highly exploited fish species that exhibit a wide range of life history strategies and reproductive patterns (Farmer et al. 2016; Biggs et al. 2017). There is extensive information on life history characteristics for most managed species, and the majority of fisheries in state and federal waters rely heavily upon life history data as the basis for assessments of both data-limited and data-rich stocks (Sagarese et al. 2015; SEDAR 2016a). There is also a growing recognition of the need to incorporate reproductive behavior in the conservation and management of these and other exploited fishes in the region (Lowerre-Barbieri et al. 2016; NOAA RESTORE Science Program, Kobara et al., 2017; Grüss et al. 2018; Erisman et al. 2018; Heyman et al., 2019). Therefore, it is a good system to compare exploitation history to spawning behavior and evaluate the degree to which more attention to spawning patterns in relation to fishing vulnerability is warranted.

The objective of this study was to investigate relationships between life history and spawning behavioral traits and identify patterns among exploited species in the GOM that have been historically overfished or may be particularly vulnerable to exploitation during the spawning season. We employed multiple methods to evaluate these relationships. First, we used a data synthesis approach to test whether life history and spawning behavioral traits were correlated. Second, we used ordination to identify groups of traits (life history and spawning behavior) that were common among overfished species. Third, we conducted a vulnerability analysis to identify species and stocks that are likely highly vulnerable during the spawning season and should be prioritized for further research and monitoring. The results indicate whether including spawning behavior characteristics can improve our ability to assess the vulnerability and resilience of marine fishes to exploitation. Additionally, this information will identify important data gaps in our understanding of the spawning behavior of exploited marine fishes and provide the basis for further research on interactions between spawning behavior and fishing activities. This information will be applicable to the management and monitoring of exploited marine fishes in the GOM, and the approach should be transferable to regional vulnerability assessments of fish stocks elsewhere.

\section{Materials \& Methods}

\section{Species selection}

A hierarchical ranking process was used to identify a manageable number of relevant species to include in the analysis (Biggs et al. 2017). The preliminary list of species included commonly occurring and commonly caught recreational or commercial species that inhabit either offshore, coastal or estuarine waters of the GOM, including all species managed in United States federal waters by the Gulf of Mexico Fisheries Management Council (GMFMC). Species were scored based on their aggregating behavior associated with spawning and a fisheries index, which included two aspects of management status (inclusion in GMFMC's fisheries management plan and NOAA's fish stock sustainability index; https://www.fisheries.noaa.gov), importance to commercial fisheries (based on total annual landings in $\mathrm{kg}$.), importance to recreational fisheries (based on total annual landing in number of fish), and their endangered status according to the 
188 IUCN Red List (https://www.iucnredlist.org). A detailed description of the selection process is

189 available in supplemental material (S1).

190

191

192

193

194

195

196

197

198

199

200

201

202

203

204

205

206

207

208

209

210

211

212

213

214

215

216

217

218

219

220

221

222

223

224

225

226

227

228

229

230

231

232

233

\section{Life history and spawning behavioral traits}

We compiled information on the life history and spawning behavior for the selected species through reviews of primary literature, technical reports, and stock assessments from NOAA's Southeast Data Assessment and Review (SEDAR; http://sedarweb.org/). Life history parameters included maximum age $\left(A_{\max }\right)$, maximum weight $\left(W_{\max }\right)$ and maximum length $\left(L_{\max }\right)$, von Bertalanffy growth coefficient $(k)$, asymptotic length $\left(L_{i n f}\right)$, age $\left(A_{m}\right)$ and length at maturity $\left(L_{m}\right)$, and rate of natural mortality $(M)$ (Table 1$)$. These parameters were chosen, because they have been shown to be directly associated with vulnerability to fishing pressure, and they are commonly used in productivity-susceptibility analyses, stock assessments, and in defining species stock complexes (Patrick et al. 2009; Robinson 2015; Farmer et al. 2016). The reported values were specific to the GOM unless there were no data, in which case information from the Atlantic or Caribbean was used. When multiple values were found, the average ( \pm SE) was used. Sexual pattern was not included in this study, because specific traits associated with sexual pattern (e.g., diagnosis, sex ratios, timing of sex change) are unknown for most hermaphroditic species in the GOM. Variations in such traits strongly influence the resilience of hermaphroditic species to fishing, often in complex ways (Robinson et al. 2017; Schram and Steele 2020), and should thus be the focus of separate study.

Spawning behavior was characterized by the degree of aggregating behavior, spawning season duration in months, and the estimated magnitude of change in relative abundance of fish during peak spawning periods relative to non-reproductive periods (Table 1). The duration of the spawning season was determined by the number of months that spawning was reported to occur in the GOM based primarily on the sampling of mature females and assessments of their reproductive condition (e.g. elevated gonadosomatic index levels or the presence of actively spawning females) (Brown-Peterson et al. 2011; Lowerre-Barbieri et al. 2011). However, some fish aggregate at spawning sites over a longer time period than active spawning occurs (Heyman et al. 2005; Heyman et al. 2019). The phrase "during spawning" refers to the spawning season and was used in this context throughout the paper.

In all cases, the values for each category were specific to the GOM, as they may vary among populations and regions along a species' geographic range (Lowerre-Barbieri et al. 2009; Heyman et al. 2019). In instances where the spawning season varied within the GOM, we incorporated the entire range of spawning months. If data related to the degree to which a species formed spawning aggregations was not available for the GOM (e.g., Epinephelus flavolimbatus), we determined their behavior based on literature from the Southeast U.S. and Caribbean (see Results and references in S3). Aggregation type was intended to reflect the distance traveled to a spawning site, and the number/distribution of spawning sites, reflected as the degree to which the species aggregates to spawn on a scale of $0-4$. Species that do not aggregate to spawn were scored 0 , simple migratory spawners were scored 1 , species that form resident aggregations were scored 2, species that form resident and transient aggregations (i.e., mixed) were scored 3, and transient aggregations were scored 4 . The estimated change in relative abundance was based on order of magnitude comparisons (e.g., 1X, 10X, 100X) between peak spawning times and abundance during non-spawning periods. The scale (1-6) distinguished among species that are solitary, grouping, or schooling for non-reproductive functions. The spawning behavior categories were ordinal in this case, because they related to varying degrees of vulnerability to

Peerj reviewing PDF | (2020:11:55081:1:0:NEW 8 Jun 2021) 
234 fishing pressure (Robinson and Samoilys 2013; Robinson, 2015). Spawning season duration and 235 the degree of aggregating behavior was obtained exclusively through a comprehensive literature

236 review. Relative abundance was based on expert judgement of the authors and collaborators

237 associated with this project.

238

239

240

241

242

243

244

245

246

247

248

249

250

251

252

253

254

255

256

257

258

259

260

261

262

263

264

265

266

267

268

269

270

271

272

273

274

275

276

277

278

279

\section{Correlation analysis and PCA}

Spearman's Rank Correlation was used to explore relationships between life history traits and spawning behavior parameters in R (R Core Team, 2016), tested at a significance level of $\alpha=0.05$. The parameters were also used to perform Principal Component Analysis (PCA) using a correlation matrix with normalized data. We could not identify reliable estimates of $M$ for the range of species of interest and thus did not integrate this trait into the PCA. A PCA was chosen rather than a Linear Discriminant Analysis (LDA) or cluster analysis, because we were interested in the continuum of reproductive behaviors and life history traits. Although PCA and k-means clustering are closely related, the PCA offers a continuous solution rather than clusters of homogenous groups (Ding and He 2004). Likewise, PCA is unsupervised and finds the directionality of maximum variance, where LDA maximizes class separability. The results of the PCA were represented with a biplot along with the stock status based on region-wide assessments in the GOM and the designations of NOAA Fisheries (https://www.fisheries.noaa.gov). "Not overfished" species were those that have never been designated as overfished. "Overfished" species included those that are currently designated or had previously been designated at some point. For example, Red Grouper were placed in the category of overfished, because previous assessments had made that designation even while newer criteria concluded that the stock has never been overfished during the time series (SEDAR 2019). "Unassessed" species were those that have not been assessed in the GOM. Harvest of Nassau Grouper (Epinephelus striatus), Atlantic Goliath Grouper (Epinephelus itajara), and Red Drum (Sciaenops ocellatus) is prohibited, because each of these stocks were historically overfished, and thus each were classified as overfished. Gag (Mycteroperca microlepis) and Red Grouper (Epinephelus morio) have also been previously designated as overfished and were labelled as such, although their current stock status is not overfished. There are no region-wide assessments for the coastal species, only limited state assessments, so those stocks were considered unassessed. A one-tailed t-test was used to compare the average PC1 and PC2 score between overfished and not overfished stocks to identify common traits among the different stock statuses. A one-tailed test was used, because each PC has directionality that is related to the theoretical vulnerability to overfishing. Lower PC1 scores and higher PC2 scores would indicate higher vulnerability.

\section{Vulnerability Analysis}

Figure 1 contains a flow chart illustrating the process of the vulnerability assessment. The vulnerability analysis was based on previous studies that accounted for life history traits and spawning behaviors associated with vulnerability to fishing during spawning (Cheung et al. 2005; Robinson and Samoilys 2013; Robinson 2015). The indicators used are split between two axes and include intrinsic indicators (life history and behavior of the species) and extrinsic indicators (behavior of the fishery and management) that measure the susceptibility and exposure of spawning fish to fishing. The intrinsic indicators included the degree of aggregating behavior associated with spawning, duration of the spawning season, change in relative abundance during spawning, $A_{\max }, L_{i n f}, A_{m}$, and $k$, as their correlation to fishing vulnerability has been previously 
280 illustrated. The extrinsic indicators reflect the degree to which spawning fish are protected within

281

282

283

284

285

286

287

288

289

290

291

292

293

294

295

296

297

298

299

300

301

302

303

304

305

306

307

308

309

310

311

312

313

314

315

316

317

318

319

320

321

322

323

324

325 state or federal waters of the GOM and included access to the fishery, catch limits, gear measures, seasonal closures and site closures during the spawning season (Table 2).

The extrinsic indicators were each scored on a scale of 1-4 with a larger number denoting a higher vulnerability. Federal regulations were considered for all species except for coastal species that are primarily targeted in state waters. For those species, state regulations were considered since they inhabit, spawn, and are fished in state waters. The assigned scores for coastal species reflected the average score among the Gulf states (Texas, Louisiana, Mississippi, Alabama, and Florida). Access to the fishery captured the extent to which access is restricted via a regulated number of permits and the individual fishing quota (IFQ) program (1), or open, requiring a basic commercial or recreational license (4). Catch limits included minimum and maximum size limits as well as daily bag limits and quotas for the commercial and recreational fishery. Scores ranged from 1 (for a total of 5 catch limits) to 4 (for no catch limits). Gear measures indicated the restrictions on gear types used in the fishery and ranged from 0 to 2 allowable gear types (1), to 9 or more allowable gear types (4). Seasonal restrictions reflected the level of spawning season prohibition of take, from prohibition during the entire spawning season (1) scaling to no restrictions (4). The selected value was the least restrictive score of recreational and commercial seasonal restrictions. Site closures ranged from total spatial closure of spawning site (1) scaling to no spatial closures (4). Scores indicated if spawning sites were closed all year or involved a complete fishery closure (1), more than or equal to $10 \%$ of known spawning sites were protected by complete or seasonal site closures (2), less than $10 \%$ of known spawning sites were protected by complete or seasonal site closures (3), or if there were no spawning site closures or the species did not reproduce in federal waters (i.e., coastal species) (4). State site closures are few and spatially minimal. Therefore, all coastal species received a score of 4 (i.e., no site-based regulations).

Reciprocal values were used for spawning season duration and $\mathrm{k}$ to preserve the direction of their influence on, and association with, increasing vulnerability. The values for life history traits $\left(A_{\max }, L_{i n f}, k\right.$, and $\left.A_{m}\right)$ were combined into one category as a life history composite. The values for each intrinsic and extrinsic indicator were scaled 0-1. Each parameter was then weighted according to the impact and relative influence on vulnerability as determined in Robinson (2015), which assigned the weights through an Analytic Hierarchy Process (Saaty 1987). The process involved ranking each parameter in terms of its influence on vulnerability and performing pair-wise comparisons to develop a matrix of indicator weights with the final value calculated as the average among the matrices. Then, the predictive ability of those weighted parameters were validated against the status of global fisheries targeting spawning aggregations (Robinson and Samoilys 2013). The validation of the vulnerability index showed the correlation of the parameters with abundance trends in seven species of reef fishes, and ultimately supported the use of the indicator-based framework (Robinson and Samoilys 2013). The respective weights for the intrinsic and extrinsic indicators are in Tables $1 \& 2$. The values were summed for each group of indicators to obtain an intrinsic and extrinsic vulnerability score. The scores along the two axes were combined to get an overall index of vulnerability to fishing during spawning, which was calculated as the Euclidian distance from the origin (position in bivariate space). Equal weight was given to intrinsic and extrinsic indicators as those compound factors were rescaled (0-1) to provide a relative comparison among the selected species.

\section{Results}




\section{Species selection}

The species selection process identified 24 species to be included in the final assessment. Four common coastal and estuarine species were added to the analysis post hoc, because they are important to fisheries in state waters throughout the GOM: Spotted Seatrout (Cynoscion nebulosus), Sheepshead (Archosargus probatocephalus), Southern Flounder (Paralichthys lethostigma), and Black Drum (Pogonias cromis). Although the selected species are not a random sample, they represent a wide range of exploited species from which to examine life history traits and spawning behavior in relation to overfishing and vulnerability, which was our objective. Although aggregating behavior in association with spawning was a main focus of the analysis, six species that do not aggregate to spawn were included among the selected species. Highly migratory, schooling, pelagic species (e.g., tunas) were excluded, because of the vastly different reproductive habitats of open ocean pelagic species. As a group, they are well studied and managed as a separate unit. This resulted in a final list of 28 species to be analyzed, which are listed on Table 3 and described in greater detail in the supplementary material (S1).

\section{Life history information and spawning behavior}

A total of 801 documents including peer-reviewed literature, grey literature, and SEDAR reports were reviewed for spawning and life history information on the 28 species. The values for each parameter are presented in Table 3, and a full table with citations for each entry is available online (http://geo.gcoos.org/restore/) and in supplementary material (S3). Values for $M$ were not found for Almaco Jack (Seriola rivoliana) or Warsaw Grouper (Hyporthodus nigritus).

The degree of aggregating behavior was determined directly from descriptions in the literature for the GOM for all species except for Warsaw Grouper and Yellowedge Grouper (Hyporthodus flavolimbatus), which were classified by the authors' expert opinions based on studies from the Southeast U.S. and Caribbean (Table 3, S3). Based on the literature review, 10 of 28 species were determined to form transient aggregations. Groupers (Epinephelidae; $n=6 ;$ ) were the most common family listed in the transient group. Seven species were categorized as forming mixed aggregations and included three grouper species, the two jacks (Carangidae) and two sciaenid (Sciaenidae) species . Five species were determined to form resident aggregations,. The two mackerel (Scomberomorus) species were designated as simple migratory spawners. Red Grouper, Snowy Grouper (Hyporthodus niveatus), Speckled Hind (Epinephelus dummondhayi), and Tilefish were determined to not form spawning aggregations based on the lack of any evidence of such behavior in the literature for the GOM or elsewhere.

The change in relative abundance of fish during spawning was greatest for Cubera Snapper (Lutjanus cyanopterus) and Nassau Grouper, which corresponded to aggregations of $>10,000$ fish (Table 3). Three additional species were classified as 5, corresponding to aggregations of 1,000-10,000 fish. Most species $(n=9)$ were scored 3, indicating that aggregations were composed of small groups of 100-200 fish. Seven species were scored a 2, corresponding to small groups or doubling of abundance relative to non-reproductive periods.

Spawning seasons ranged from 3 to 12 months, with grouper species having the largest variation in spawning season (Table 4). Yellowedge Grouper had the most protracted spawning seasons at 12 months followed by Yellowmouth Grouper (Mycteroperca interstitialis) at 10 months, while Nassau Grouper and Sheepshead only spawned three months out of the year. The greatest number of species spawned in June $(\mathrm{n}=21)$, with an average of 18 species spawning per month, April through August. The fewest number of species spawned in November $(\mathrm{n}=7)$ and 
372 December $(\mathrm{n}=4)$. The snappers were the only family that showed consistency in spawning

373 season, with peak spawning occurring June through August. An annotated table with all

374 references is available online (http://geo.gcoos.org/restore/) and in supplementary material (S3).

375

376

377

378

379

380

381

382

383

384

385

386

387

388

389

390

391

392

393

394

395

396

397

398

399

400

401

402

403

404

405

406

407

408

409

410

411

412

413

414

415

416

417

\section{Correlation analysis and PCA}

Aggregation type was positively correlated with relative abundance $\left(\mathrm{r}_{\mathrm{s}}=0.819, \mathrm{p}<0.01\right)$ (Figure 2 , Table S2.1). Spawning season duration was negatively correlated with relative abundance $\left(\mathrm{r}_{\mathrm{s}}=\right.$ $-0.538, \mathrm{p}=0.01)$ and $k\left(\mathrm{r}_{\mathrm{s}}=-0.526, \mathrm{p}=0.01\right)$. We found no other significant relationships between spawning behavior parameters and life history traits. However, most of the life history traits were significantly correlated with each other (Figure 2, Table S2.1). As expected, the maximum growth parameters (age, weight, length, $\mathrm{L}_{\text {inf }}$ ) were positively correlated with each other and $A_{m}$, and negatively correlated with $k$ and $M$.

The first two axes of the PCA explained $64.4 \%$ of the variation in the data (Figure 3, Table S2.2). Along PC2, the eigenvectors for spawning behavior characteristics had a greater influence (as defined by the absolute value of the eigenvector) on the distribution of species than life history traits. Relative abundance (0.634) was the greatest followed by aggregation type (0.493) and spawning season duration (-0.481). Along PC1, the eigenvectors for life history traits had a greater influence than those for spawning behaviors. $L_{m}$ was the greatest $(-0.440)$, followed by $L_{\text {inf }}(-0.430), L_{\max }(-0.405)$, and $W_{\max }(-0.399)$. The PCA biplot (Figure 3$)$ illustrates the separation of species by the reproductive and life history parameters along the first two PC axes within the context of stock status. Six of the species have been deemed not overfished. Ten species have been overfished, including Atlantic Goliath Grouper and Nassau Grouper, which are both closed to recreational and commercial fishing, as well as Red Drum, which is closed to fishing in federal waters and to commercial fishing in most states along the GOM. Twelve species have not been assessed, including three coastal species. The PC2 scores were positive for 7 out of 10 species that are currently or historically overfished whereas they were negative for 4 of the 6 not overfished species. The mean PC score was significantly higher for stocks currently or historically overfished than not overfished for PC2 $(t=2.03, \mathrm{df}=9.25, \mathrm{p}=0.04)$ but not for $\mathrm{PC} 1(\mathrm{t}=-0.844, \mathrm{df}=15, \mathrm{p}=0.79)$ (Figure 4$)$. Overfished status was closely associated with positive changes in relative abundance and aggregation type, and negatively related to spawning season duration. Peak spawning months was included in an additional PCA, but it did not change the output and had very low eigenvectors, so it was not considered further (Figure S2.1).

\section{Vulnerability analysis}

Scores for the intrinsic and extrinsic vulnerability analysis along with the extrinsic indicator scores for federal and state management regulations are available in supplemental material (S4). Sheepshead and Southern Flounder had the two greatest overall vulnerability scores, but neither are federally managed nor have they been assessed at the region-wide level (Figure 5). Cubera Snapper had the greatest vulnerability scores among the federally managed species, but the stock has not been assessed. All species scored high in extrinsic vulnerability $(>0.5)$, except for Gray Triggerfish (Balistes capriscus) and the three species with closed fisheries (Atlantic Goliath Grouper, Nassau Grouper, Red Drum) that also had the lowest overall vulnerability scores. The intrinsic vulnerability score was greatest for Nassau Grouper and least for Spanish Mackerel (Scomberomorus maculatus). Cubera Snapper, Warsaw Grouper, and Yellowmouth Grouper had the highest intrinsic vulnerability scores among the unassessed species. 


\section{Discussion}

419 Spawning behavior represents a separate and distinct aspect of fish ecology that is important to 420 consider for accurate predictions of vulnerability and resilience in exploited stocks (Erisman et

421

422

423

424

425

426

427

428

429

430

431

432

433

434

435

436

437

438

439

440

441

442

443

444

445

446

447

448

449

450

451

452

453

454

455

456

457

458

459

460

461

462

463 al. 2017a,b; Lowerre-Barbieri et al. 2017). Our results show that characteristics of spawning behavior known to be associated with vulnerability to fishing are not directly related to life history traits that are typically associated with vulnerability in 28 species of exploited marine fishes in the GOM. Using PCA analysis, we demonstrated that the characterization of spawning behaviors improved the identification of vulnerable and overfished species more than "traditional" life history traits alone. We found that nearly all species showed susceptibility to overfishing or becoming overfished during their spawning season due to very few state or federal regulations to protect spawning fish in the GOM. However, there was a large range of intrinsic vulnerability based on the diversity of spawning behavior and life history traits exhibited among the species studied. Increased effort to understand patterns of spawning behavior and the distribution of fishing effort and catch in relation to spawning would aid conservation and management efforts in the GOM. Specifically, it would help identify species that are particularly vulnerable to fishing during spawning and support the enactment of protection measures to enhance resilience to fisheries exploitation (Erisman et al. 2018; Heyman et al. 2019). Consideration of spawning dynamics in addition to more traditional life history traits, management, and fisher behavior would help focus monitoring, research, and rebuilding efforts on the most vulnerable species. In the U.S. GOM, stock assessments generate a probability distribution function of overfishing limits that is converted to allowable biological catch based on the Gulf Council's risk tolerance for scientific uncertainty. Our findings imply a larger buffer may be necessary to avoid overfishing for transient aggregating species, especially when this spawning behavior is not explicitly considered in stock assessment.

There was a clear separation between life history traits and spawning behavior with respect to loadings along the first two principal component axes. The component scores along PC1 separated species based on life history traits, and PC2 was primarily loaded with spawning behaviors. Spawning behavior provided a better distinction between overfished and notoverfished species than the life history traits (i.e., more status information can be derived from PC2 than PC1). Stock status of a fishery is influenced by multiple factors, which include extrinsic components such as fishing practices (e.g., fishing effort; gear efficiency and selectivity), management actions, stock assessment uncertainty stemming from data limitations in the indicators (e.g., biomass), and changes in biological reference points (Rosenberg and Restrepo 1994; Branch et al. 2011). We acknowledge that stock status may not completely reflect the vulnerability and resilience of a species, but it is commonly assumed to be a function of life history traits and historical exploitation (Costello et al. 2012). In addition, stock status provides a metric to compare the relationships between exploitation, life history and reproductive behavior, especially with respect to identifying species that might be at risk of overfishing. Several unassessed stocks with high intrinsic and extrinsic vulnerability were identified, including deep-water grouper stocks such as Speckled Hind and Warsaw Grouper. In the nearby U.S. South Atlantic region, spatial protections for these stocks have been considered, to reduce post-release mortality (Farmer \& Karnauskas 2013) and then implemented by creating a declaration of five new Spawning Special Management Zones (sSMZs) in which bottom fishing is restricted (South Atlantic Fisheries Management Council 2017).

As has been shown in several review studies on spawning aggregations (e.g., Erisman et al. 2011; Sadovy de Mitcheson and Erisman 2012), species with spawning behaviors 
464 characterized by transient aggregations (that form over short durations and have large changes in 465 relative abundance) were more likely to be overfished than those that form resident aggregations, 466 mixed aggregations, or do not aggregate for spawning. Therefore, the consideration of spawning 467 behaviors offers a useful augmentation to the concept that slow-growing, long-lived and late 468 maturing species are always the most vulnerable to become overfished. Productivity 469 susceptibility analyses that rely heavily on life history traits have been used to identify at-risk 470 species (Hobday et al. 2011; Patrick et al. 2010), but they have also received criticism for their 471 inability to discriminate risk among species, except in the most extreme cases (Hordyk and 472 Carruthers 2018). Since a relationship between spawning behaviors and vulnerability has been 473 observed (Erisman et al. 2011; Sadovy de Mitcheson and Erisman 2012), and spawning 474 behaviors are distinct from other life history traits, incorporating reproductive behaviors may 475 improve the discriminatory power of vulnerability analyses. Despite the issues and limitations 476 with discriminatory power, it is clear from the results of this study that the completion of a 477 vulnerability analysis that includes spawning behavior remains a valuable management exercise 478 to identify those species most vulnerable to fishing during spawning (i.e., extreme cases). The 479 results clearly define higher vulnerability and shows utility for prioritizing future research and 480 improving monitoring efforts.

Vulnerability scores displayed increasing trends with species that exhibit large changes in relative abundance, have short spawning seasons and form transient aggregations, which is expected because those components are included in the calculation of intrinsic vulnerability. However, it is noteworthy that those trends persist because the overall vulnerability score includes extrinsic vulnerability factors, and the life history composite was more heavily weighted as an influence on vulnerability than any of the spawning behaviors. Species with short spawning seasons that form transient spawning aggregations are prone to experience rapid depletion in response to targeted fishing pressure of spawners and slower recovery rates due to impacts on spatiotemporal egg production and stock recruitment relationships (Claro et al. 2009; Erisman et al. 2012; Sadovy De Mitcheson and Erisman 2012). Yet, such declines can be difficult to detect using traditional, catch-based methods of estimating abundance or when historical information is unavailable (Erisman et al. 2011; Maunder and Deriso 2013; Lowerre-Barbieri et al. 2015). Large increases in relative abundance during spawning are linked to enhanced catchability for most species that aggregate (Ellis and Wang 2007; Wilberg et al. 2009). For those species, the increased catchability during spawning can also lead to hyperstability in which catch per unit effort (CPUE) remains high even while the actual abundance of the stock decreases in response to fishing mortality (Erisman et al. 2011). As a result, overfishing and stock declines may remain undetected until after sudden, large decreases in catch or CPUE occur (Rose and Kulka 1999).

In contrast with a standard productivity susceptibility analysis (e.g., Patrick et al. 2010), our vulnerability analysis followed the approach of Robinson and Samoilys (2013) and Robinson (2015) by focusing specifically on identifying species that are highly sensitive to fishing during spawning. Extrinsic vulnerability was high for 25 of the 28 species, which reflects the high level of exposure to fishing during spawning throughout the GOM, and the existing threat of overfishing via the targeted, pervasive exploitation of spawning fish by commercial and recreational fishing activities (Grüss et al. 2018; Grüss et al. 2019; Heyman et al. 2019). The level of compliance with any of the regulations may vary and can greatly influence the effectiveness of the measure, but the regulations do serve as a metric of the perceived vulnerability by managers. Future research focused on assessing fishing effort, catch, and catchability (e.g., CPUE) patterns in relation to spawning as well as trends in market sales and 
510 values during spawning seasons would likely improve our understanding of vulnerability and the 511 impacts of harvesting spawning fish on stock resilience for exploited fishes in the GOM

512 (Erisman et al. 2018; Heyman et al. 2019). Understanding these behavioral impacts on resilience

513 allows managers to better target management measures on spawning for those species most

514 vulnerable to fishing due to such behaviors and discount those factors for species less vulnerable 515 to spawning behaviors.

516 A detailed exploration of six important species further illustrates the management

517 implications of our results. These species include examples of both coastal and reef fishes whose

518 spawning behaviors fall along a continuum of intrinsic vulnerability scores (Table S4), ranging

519 between resident (Spotted Seatrout, Red Snapper), mixed (Red Drum and Greater Amberjack),

520 and transient aggregating species (Gag, Atlantic Goliath Grouper) (Table S3, Figure 5). Red

521 Drum and Spotted Seatrout are the two most important and valuable species for inshore

522 recreational fisheries throughout the GOM (Blanchet et al. 2001; NMFS 2018). Red Snapper

523 (Lutjanus campechanus) is arguably the most important and politically contentious commercial

524 and recreational fishery in the GOM (Farmer et al. 2020). Both Greater Amberjack and Gag are

525 also valuable, highly targeted species for both the recreational and commercial sectors in the

526 GOM that aggregate to spawn. Finally, Atlantic Goliath Grouper have been closed to

527

528

529

530

531

532

533 commercial and recreational harvest in state and federal waters of the GOM since 1990 due to severe population declines associated with overfishing of their transient spawning aggregations (Koenig et al. 2020).

Spotted Seatrout are classified as resident spawners, because they have a protracted spawning season (April - September; Table S3), and spawning occurs on a daily basis within small (i.e., 10s to a few hundred individuals) resident aggregations that persist at many locations and habitat types along the coast and throughout estuaries (Saucier and Baltz 1993; Walters et al. 2009; Biggs et al. 2018). Although Spotted Seatrout are managed at the state level and not assessed regionally, harvest levels have remained stable over the last 20 years in most areas (NMFS 2018). Their resilience to persistent, intense fishing pressure is believed to be linked to their high level of spawning productivity, both spatially and temporally (Biggs et al. 2018). For this reason, traditional catch controls such as daily bag and minimum size limits appear to be sufficient to maintain populations, and the targeted protection (e.g., seasonal restrictions or area closures) of spawning fish is not a priority for management.

Red snapper form schools of hundreds to thousands of fish throughout the year across a broad array of coastal and offshore habitats (e.g. natural and artificial reefs, petroleum platforms) in the GOM (Patterson et al. 2007; Erisman et al. 2020). At the population level, spawning occurs continuously from May through September in small groups within these localized schools rather than concentrating spawning at a few, highly populated sites (Porch et al. 2015; Farmer et al. 2017; Glenn et al. 2017). While fishers have reported the previous existence of large spawning aggregation sites of Red snapper (Lindeman et al. 2000), there is no evidence that coordinated migrations to specific spawning sites occurs or that densities or relative abundance at spawning sites is markedly higher than non-spawning sites (Patterson et al. 2007; Szedlmayer and Bortone, 2019). Based on this information, we classified the species as resident aggregation spawners, but it would also be reasonable to classify the species as non-aggregating based on the specific criteria used (Domeier 2012; Claydon et al. 2014). Regardless, the more important point is that the spatiotemporal dynamics of spawning behavior should confer reproductive resilience to intense fishing effort during the spawning season (i.e. low overall vulnerability), which is supported by the results of this study and the status of the regional stock. 
556 Fishing effort and landings for Red snapper in federal waters peak during the summer months in 557 association with the recreational fishing season, which coincides with the peak spawning season 558 for this species (Heyman et al. 2019). Nevertheless, rebuilding of the stock has occurred in response to strict catch and effort controls implemented at state and federal levels that did not focus on spawning (SEDAR 2018; Farmer et al. 2020).

Both Red Drum and Greater Amberjack (Seriola dumerili) are classified as mixed spawners (Table S3) with an intermediate level of intrinsic vulnerability to fishing in relation to spawning (Table S4). Red Drum are known to form large transient (hundreds to tens of thousands of individuals) spawning aggregations that occur predictably at the mouths of estuaries and tidal inlets throughout the GOM from August to November, but these aggregations are not limited to discrete locations within such habitats, adults school year round, and resident aggregations have been reported as well (Pearson 1928; Holt 2008; Lowerre-Barbieri et al. 2016; Lowerre-Barbieri et al. 2019). Although the fishery is closed in federal waters, it is open to recreational fishing in state waters throughout the GOM and commercially in state waters in Mississippi (Heyman et al. 2019). A rapid increase in the targeted harvesting of adult fish from their spawning aggregations by the commercial fishery during the mid-1980s led to overfishing and the closure of the federal fishery (Porch 2000). However, recreational anglers continue to target these well-known spawning aggregations during the late summer and fall months and this activity peaks during the spawning season, but the impacts of this interaction on the population or the fishery have not been assessed. Similar to Red Drum, Greater Amberjack spawning behavior is classified as mixed with a spawning season from March to June in the GOM with regional variations in seasonality (Table S3). Commercial landings in federal waters are prohibited during the peak spawning season (March-May), while recreational landings for Greater Amberjack are closed during the end and after the spawning season (June-July) (SEDAR 2014a). Recreational landings are consistently higher during the spawning season than the nonspawning season (Kobara et al. 2017; Heyman et al. 2019), but the impacts of fishing during spawning have not been evaluated.

Gag and Goliath Grouper are both transient spawners (Table S3) with a high intrinsic vulnerability to fishing during spawning in the GOM (Table S4). Gag exhibit complex reproductive ecology in which females form pre-spawning aggregations in coastal waters before migrating offshore to deep-water spawning sites in the winter where males tend to occur yearround (Koenig et al. 1996; Carruthers et al. 2015). The species is also protogynous, in which female to male sex change occurs during both the pre-spawning aggregations and at the spawning grounds (Lowerre-Barbieri et al. 2020). Unlike typical transient spawning aggregations that involve group spawning and hundreds to thousands of fish, Gag aggregations are comprised of tens to a few hundred fish and courtship occurs in pairs (Gilmore and Jones 1992; Coleman et al. 1996; Lowerre-Barbieri et al. 2020). GOM Gag were overfished and undergoing overfishing in the 1990s, with heavy fishing on Gag spawning aggregations that resulted in the severe reduction of males, which contributed to stock declines (Coleman et al. 1996). Consequently, the protection of spawning Gag has long been a focal point for management and the rebuilding of the stock (SEDAR 2014b; SEDAR 2016b). Recent studies have demonstrated that Gag biomass and fishing pressure are highest in nearshore waters, pre-spawning aggregations are a spatiotemporal bottleneck to population productivity, and current regulations are not sufficient for the male population to recover to historic levels (Carruthers et al. 2015; Lowerre-Barbieri et al. 2020). Similar to Gag, Atlantic Goliath Grouper may migrate long distances (up to $500 \mathrm{~km}$ ) to specific sites to spawn within transient spawning aggregations that form from late July through October 
602 (Koenig et al. 2017). Severe population declines occurred in the GOM from the 1950s through

603 the 1980s due in part to overfishing of spawning aggregations, but the species has shown signs of 604 recovery following their complete protection from exploitation in state and federal waters in

6051990 (Koenig et al. 2011).

606 One of the challenges to incorporating details of reproductive behavior within

607 assessments and management is the paucity of information available. For example, discrete

608 quantitative information on changes in the relative abundance (e.g., increases in fish density and

609 abundance during formation of spawning aggregations) of fish within a given area in relation to

610 spawning activity is rare and currently, has only published for red drum (Lowerre-Barbieri et al.,

611 2019) and Gag (Lowerre-Barbieri et al., 2020). This represents a critical data gap relevant to the

612 management of fish stocks in the GOM. Further, changes in relative abundance are directly tied

613 to changes in catchability, which is widely accepted as a crucial component of vulnerability

614 (Arreguín-Sánchez 1999; Salthaug and Aanes 2003; Wilberg et al. 2009) and as mentioned

615 above, hyperstability. Our results also demonstrate that relative abundance is an important factor

616 as it was not correlated to any life history traits. Therefore, it represents an independent aspect of

617 reproductive behavior relevant to assessing vulnerability and should be the focus of further

618 research for those species that form spawning aggregations that are targeted and heavily

619 exploited by recreational or commercial fishing.

620 In contrast to changes in the relative abundance of fish during spawning, spawning

621 seasons are well documented in the literature. However, spawning seasons are usually reported

622

623

624

625

626

627

628

629 on a monthly scale, which does not capture the finer variations in spawning periodicity, the degree of aggregating behavior, or the distribution of spawning sites among species. For example, Cubera Snapper spawn from June through September, but aggregations only form at a few sites for 1-2 weeks each month, and actual spawning is restricted to just a few days within a single aggregation period (Heyman et al. 2005; Biggs and Nemeth 2016). Nassau Grouper, Mutton Snapper, and other GOM species in the grouper-snapper complex exhibit similar behaviors in which spawning occurs over a few days within large aggregations that form at specific sites in synchrony with lunar (or semilunar) rhythms (Heyman and Kjerve 2008). On the

630 other end of the behavioral spectrum, species such as Spotted Seatrout and Red Snapper can

631 spawn daily (population level) over the course of 5 to 6 months, and spawning sites are numerous and widely distributed (Walters et al., 2009; Lowerre-Barbieri et al., 2015; Glenn et al. 2017; Biggs et al. 2018). Differences in the spatiotemporal dynamics of spawning affects their respective vulnerability, but much of that variation is captured in the categorization of aggregation type (e.g., Cubera Snapper form transient aggregations and Spotted Seatrout form resident aggregations).

637

638

There is also some potential variation with respect to aggregation type across the region.

639

640

641

642

643

644

645

646 For example, studies on the reproductive behavior of Red Grouper conducted in the U.S. GOM have all concluded that this species does not migrate during spawning or form spawning aggregations. Red grouper exhibit a haremic mating system in which resident males pair spawn with individual females that reside in small groups within its home territory (Coleman et al. 2011; Nelson et al. 2011; Wall et al. 2011). Conversely, studies of Red Grouper fisheries and populations off Campeche, Mexico in the southern GOM do refer to spawning aggregations based on inferences drawn from increases in catchability and catch-per-unit effort during the spawning season at spawning sites (López-Rocha et al. 2009; López-Rocha and Arreguín-

647 Sánchez 2013). These discrepancies further demonstrate the importance of fisheries-independent research on spawning dynamics and behavior to inform fisheries management (e.g., areal or 
648

649

650

651

652

653

654

655

656

657

658

659

660

661

662

663

664

665

666

667

668

669

670

671

672

673

674

675

676

677

678

679

680

681

682

683

684

685

686

687

688

689

690

691

seasonal restrictions), including investigations of behavioral traits that may vary on regional scales within the GOM.

The benefit of the approach used in this study is that it can be used to inform state and federal management groups by identifying and prioritizing which species should be targeted for research, monitoring, and management actions in the absence of formal stock assessments. Of the species in our analysis that have not been assessed through formal stock assessments, Cubera Snapper, Warsaw Grouper, Sheepshead, Southern Flounder, and Black Drum are likely at risk of overfishing due to strong interactions between fishing and spawning. These species all exhibit reproductive behaviors that indicate they should be assessed in the GOM and that interactions between fishing and spawning should be investigated further to determine if spawning fish would benefit from additional protection (e.g., seasonal catch limits or inclusion with marine protected areas). Additionally, this approach can be applied to other regions and fisheries. As one example, the U.S. South Atlantic region contains many of the same harvested species as the GOM, but the stocks are managed separately and have different regulations in both state and federal waters. Additionally, the spawning seasons, locations, and environmental cues to spawning are well described for many stocks in the U.S. South Atlantic (Farmer et al. 2017). Therefore, our analysis can be transferred to that region with only minor adjustments to account for the differences in extrinsic vulnerability parameters. Our analysis also provides the framework to identify and prioritize management and monitoring of species that are vulnerable to fishing during spawning, which is especially important and applicable in areas where management resources, monitoring effort and fisheries data are limited (e.g., Caribbean, Tropical Eastern Pacific, Indo-Pacific) (Salas et al. 2007; Gill et al. 2017). Moreover, quantitative information on the periodicity and frequency of spawning and other spatiotemporal aspects of spawning behavior can be directly incorporated into estimates of annual reproductive output and spawning potential ratios (Cooper et al. 2013; Erisman et al. 2014, 2020; Lowerre-Barbieri et al. 2017), thus representing a clear pathway to incorporate such valuable information within formal stock assessments.

\section{Conclusions}

Exploited marine fish species displaying similar life history characteristics can be very different with regards to their vulnerability and resilience to fishing when reproductive behavior is considered. This distinction is meaningful, because spawning behaviors are underrepresented in the conservation or management plans of most marine fishes species in the GOM and elsewhere. Based on the results of this study, it is important to consider both aspects within management frameworks, particularly for those species known to form large, transient spawning aggregations that are targeted by commercial and recreational fishing activities. Assessing the vulnerability of a marine fish species based on their size, longevity, and maturation rate alone may not capture the true complexity of their biology and likewise their resilience or vulnerability to fishing pressure, particularly when fishing efforts target spawning sites, seasons, or the actual spawning period itself. As a result, incorporating spawning behavior within such analyses can significantly improve our understanding of vulnerability. By extension, the lack of biological and fisheries information on reproductive behavior hampers efforts to maintain healthy, productive stocks to benefit fisheries and ecosystems. Moreover, these types of bivariate frameworks can be a valuable tool for understanding the main factors underlying vulnerability of marine fishes and for 
692 prioritizing research and management around those species showing the greatest vulnerability to

693 fishing during spawning.

694

\section{Acknowledgements}

696 We are grateful to the many people that provided data, feedback, or other valuable support for

697 this study including M. Karnauskas, W. Stearns, F. Parker, J. Lartigue, C. Young, A. Grüss, D.

698 DeMaria, S. Hickman, K. Guindon, S. Cantrell, V. Ventura, W. Werner, D. Naar, S. Murawski,

699 M. Russell, C. Taylor, T. Kellison, R. Williams, R. Crabtree, L. Crabtree, E. Reed, C. Koenig, K.

700 Boswell, S. Fulton, J. Locascio, J. Brenner, B. Kirkpatrick, B. Gallaway, K. McCain, T.

701 Wheatley, H. Binns, A. Acosta, A. Trotter, F. Giordano, F. Helies, R. Ellis, H. Staley, K.

702 Faherty-Walia, R. Devictor, G.P. Schmall, B. Gorst, T. Loughran, L. Yeager, L. Fuiman, and

703 many others.

704

705

706

707

708

Disclaimer: The scientific results and conclusions, as well as any views or opinions expressed herein, are those of the author(s) and do not necessarily reflect those of NOAA or the Department of Commerce.

709

\section{Author Contributions}

711

712

713

714

715

716

717

718

719

720

721

722

723

724

725

726

727

728

729
- Christopher R. Biggs conceived the study, compiled the data, designed the analytical framework, analyzed the data, prepared the figures and tables, wrote the paper, reviewed and edited drafts of the paper, and approved the final draft.

- William Heyman compiled the data, wrote the paper, reviewed and edited drafts of the paper, and approved the final draft.

- Nicholas A. Farmer compiled the data, reviewed and edited drafts of the paper, and approved the final draft.

- Derek G. Bolser compiled the data, analyzed the data, reviewed and edited drafts of the paper, and approved the final draft.

- Shinichi Kobara compiled the data, reviewed and edited drafts of the paper, and approved the final draft.

- Jan Robinson designed the analytical framework, reviewed and edited drafts of the paper, and approved the final draft.

- Susan K. Lowerre-Barbieri reviewed and edited drafts of the paper and approved the final draft.

- Brad E. Erisman led the project associated with this study as senior investigator, conceived of the study, compiled the data, designed the analytical framework, analyzed the data, wrote the paper, reviewed and edited drafts of the paper, and approved the final draft. 


\section{References}

732 Adams, P. B. 1980. Life history patterns in marine fishes and their consequences for fisheries

733

734

735

736

737

738

739

740

741

742

743

744

745

746

747

748

749

750

751

752

753

754

755

756

757

758

759

760

761

762

763

764

765

766

767

768

769

770

771

772

773

774

775

776 management. Fishery Bulletin 78:1-12.

Arreguín-Sánchez, F. 1996. Catchability: a key parameter for fish stock assessment. Reviews in Fish Biology and Fisheries 6:221-242.

Arreguín-Sánchez, F. 1999. Catchability estimates and their application to the red grouper (Epinephelus morio) fishery of the Campeche Bank, Mexico. Fishery Bulletin, 1999 24(3):282.

Biggs, C. R., B. E. Erisman, W. D. Heyman, S. Kobara, N. Farmer, S. Lowerre-Barbieri, M. Karnauskas, and J. Brenner. 2017. Species selection for evaluation with spawning aggregation and fisheries management criteria. Cooperative monitoring program for spawning aggregations in the Gulf of Mexico. Available at: https://geo.gcoos.org/restore/selection_criteria.

Biggs, C. R., S. Lowerre-Barbieri, and B. Erisman. 2018. Reproductive resilience of an estuarine fish in the eye of a hurricane. Biology Letters 14:10-14.

Biggs, C. R., and R. Nemeth. 2016. Spatial and temporal movement patterns of two snapper species at a multi-species spawning aggregation. Marine Ecology Progress Series 558:129142.

Blanchet, H., M. Van Hoose, L. McEachron, B. Muller, J. Warren, J. Gill, T. Waldrop, J. Waller, C. Adams, R. B. Ditton, D. Shively, and S. VanderKooy. 2001. The spotted seatrout fishery of the Gulf of Mexico, United States: A regional management plan. Gulf States Marine Fisheries Commission 87:1-204.

Branch, T. A., O. P. Jensen, D. Ricard, Y. Ye, and R. Hilborn. 2011. Contrasting global trends in marine fishery status obtained from catches and from stock assessments. Conservation Biology 25(4):777-786.

Brown-Peterson, N. J., D. M. Wyanski, F. Saborido-Rey, B. J. Macewicz, and S. K. LowerreBarbieri. 2011. A standardized terminology for describing reproductive development in fishes. Marine and Coastal Fisheries, 3(1):52-70.

Carruthers, T.R., Walter, J.F., McAllister, M.K., Bryan, M.D., and M. Wilberg. 2015. Modelling age-dependent movement: an application to red and gag groupers in the Gulf of Mexico. Canadian Journal of Fisheries and Aquatic Science 72: 1159-1176.

Cheung, W. W. L., T. J. Pitcher, and D. Pauly. 2005. A fuzzy logic expert system to estimate intrinsic extinction vulnerabilities of marine fishes to fishing. Biological Conservation 124(1):97-111.

Cheung, W. W. L., Y. Sadovy de Mitcheson, M. T. Braynen, and L. G. Gittens. 2013. Are the last remaining Nassau grouper Epinephelus striatus fisheries sustainable? Status quo in the Bahamas. Endangered Species Research 20(1):27-39.

Choat, H. 2012. Spawning Aggregations in Reef Fishes; Ecological and Evolutionary Processes. Pages 85-116 in Y. Sadovy and P. L. Colin, editors. Reef Fish Spawning Aggregations: Biology, Research and Management, 1st edition. Springer.

Cinner, J. E., T. R. Mcclanahan, T. M. Daw, N. A. J. Graham, J. Maina, S. K. Wilson, and T. P. Hughes. 2009. Report linking social and ecological systems to sustain coral reef fisheries. Current Biology 19:206-212.

Claro, R., Y. Sadovy de Mitcheson, K. C. Lindeman, and A. R. García-Cagide. 2009. Historical analysis of Cuban commercial fishing effort and the effects of management interventions on important reef fishes from 1960-2005. Fisheries Research 99(1):7-16. 
777

778

779

780

781

782

783

784

785

786

787

788

789

790

791

792

793

794

795

796

797

798

799

800

801

802

803

804

805

806

807

808

809

810

811

812

813

814

815

816

817

818

819

820

821

822

Claydon, J., M. I. Mccormick, and G. P. Jones. 2014. Multispecies spawning sites for fishes on a low-latitude coral reef: Spatial and temporal patterns. Journal of Fish Biology 84(4):11361163.

Coleman, F.C., Koenig, C.C. and Collins, L.A. 1996. Reproductive styles of shallow-water groupers (Pisces: Serranidae) in the eastern Gulf of Mexico and the consequences of fishing spawning aggregations. Environmental Biology of Fishes 47(2):129-141.

Coleman, F. C., K. M. Scanlon, and C. C. Koenig. 2011. Groupers on the edge: shelf edge spawning habitat in and around marine reserves of the Northeastern Gulf of Mexico. Professional Geographer 63(4):456-474.

Cooper, W. T., L. R. Barbieri, M. D. Murphy, and S. Lowerre-Barbieri. 2013. Assessing stock reproductive potential in species with indeterminate fecundity: Effects of age truncation and size-dependent reproductive timing. Fisheries Research 138:31-41.

Coulson, P. G. 2019. The life-history of Cheilodactylus rubrolabiatus from south-western Australia and comparison of biological characteristics of the Cheilodactylidae and Latridae: support for an amalgamation of families. Journal of Fish Biology 94(3):374-390.

Costello, C., D. Ovando, R. Hilborn, S. D. Gaines, O. Deschenes, and S. E. Lester. 2012. Status and solutions for the world's unassessed fisheries. Science (September):1-4.

Davies, T. D., and J. K. Baum. 2012. Extinction risk and overfishing: Reconciling conservation and fisheries perspectives on the status of marine fishes. Scientific Reports 2(1):1-9.

Ding, C., and X. He. 2004. K-means clustering via principal component analysis. Proceedings of the twenty-first international conference on Machine learning (21):29.

Domeier, M. L. 2012. Revisiting Spawning Aggregations: Definitions and Challenges. Page 20 in Y. Sadovy De Mitcheson and P. L. Colin, editors. Reef fish spawning aggregations: Biology, Research and Management. Springer Netherlands.

Donahue, M. J., M. Karnauskas, C. Toews, and C. B. Paris. 2015. Location isn't everything: Timing of spawning aggregations optimizes larval replenishment. PLoS ONE 10(6):1-14.

Dulvy, N. K., J. R. Ellis, N. B. Goodwin, A. Grant, J. D. Reynolds, and S. Jennings. 2004. Methods of assessing extinction risk in marine fishes. Fish and Fisheries 5(3):255-276.

Ellis, N., and Y.G. Wang. 2007. Effects of fish density distribution and effort distribution on catchability, ICES Journal of Marine Science 64 (1): 178-191.

Erisman, B., L. G. Allen, J. T. Claisse, D. J. Pondella II, E. F. Miller, and J. H. Murray. 2011. The illusion of plenty: hyperstability masks collapses in two recreational fisheries that target fish spawning aggregations. Canadian Journal of Fisheries and Aquatic Sciences 68:17051716.

Erisman, B., O. Aburto-Oropeza, C. Gonzalez-Abraham, I. Mascareñas-Osorio, M. MorenoBáez, and P.A. Hastings. 2012. Spatiotemporal dynamics of a fish spawning aggregation and its fishery in the Gulf of California. Scientific Reports 2: 284.

Erisman, B. E., A. M. Apel, A. D. MacCall, M. J. Román, and R. Fujita. 2014. The influence of gear selectivity and spawning behavior on a data-poor assessment of a spawning aggregation fishery. Fisheries Research 159:75-87. Elsevier B.V.

Erisman, B., W. Heyman, S. Kobara, T. Ezer, S. Pittman, O. Aburto-Oropeza, and R. S. Nemeth. 2017a. Fish spawning aggregations: where well-placed management actions can yield big benefits for fisheries and conservation. Fish and Fisheries 18(1):128-144.

Erisman, B. E., J. J. Cota-Nieto, M. Moreno-Báez, and O. Aburto-Oropeza. 2017b. Vulnerability of spawning aggregations of a coastal marine fish to a small-scale fishery. Marine Biology 164(5):1-18. Springer Verlag.

PeerJ reviewing PDF | (2020:11:55081:1:0:NEW 8 Jun 2021) 
823 Erisman, B., W. Heyman, S. Kobara, C. Biggs, A. Grüss, M. Karnauskas, S. Lowerre-Barbieri,

824

825

826

827

828

829

830

831

832

833

834

835

836

837

838

839

840

841

842

843

844

845

846

847

848

849

850

851

852

853

854

855

856

857

858

859

860

861

862

863

864

865

866

867

868
D. Bolser, J. Brenner, N. Farmer. 2018. Cooperative Monitoring Program for Spawning Aggregations in the Gulf of Mexico: An Assessment of Existing Information, Data Gaps, and Research Priorities. NOAA RESTORE Science Program, Final Report, November 2018. 32 pp. Available at: https://geo.gcoos.org/restore/finalreport

Erisman, B. E., A. Grüss, I. Mascareñas-Osorio, H. Lícon-González, A. F. Johnson, and C. López-Sagástegui. 2020. Balancing conservation and utilization in spawning aggregation fisheries: a trade-off analysis of an overexploited marine fish. ICES Journal of Marine Science 77(1): 148-161.

Farmer, N.A., Heyman, W.D., Karnauskas, M., Kobara, S., Smart, T., Ballenger, J., Reichert, M., Wyanski, D., Tishler, M.S., Lindeman, K.C., Lowerre-Barbieri, S., Switzer, T., Solomon, J., McCain, K., Marhefka, M., Sedberry, G.R. 2017. Timing and location of reef fish spawning off the southeastern United States. PLoS ONE 12(3):e0172968.

Farmer, N.A., Karnauskas, M. 2013. Spatial distribution and conservation of speckled hind and warsaw grouper in the Atlantic Ocean off the southeastern U.S. PLoS One, 8(11):e78682.

Farmer, N.A., J.T. Froeschke, and D.L. Records. 2020. Forecasting for recreational fisheries management: a derby fishery case study with Gulf of Mexico Red Snapper, ICES Journal of Marine Science 77(6): 2265-2284.

Farmer, N. A., R. P. Malinowski, M. F. McGovern, and P. J. Rubec. 2016. Stock complexes for fisheries management in the Gulf of Mexico. Marine and Coastal Fisheries 8(1):177-201.

Frisk, M., T. J. Miller, and N. K. Dulvy. 2005. Life histories and vulnerability to exploitation of elasmobranchs: inferences from elasticity, perturbation and phylogenetic analyses. Journal of Northwest Atlantic Fishery Science 35:27-45.

Ganias, K., S. Somarakis, and C. Nunes. 2014. Reproductive potential. Pages 79-121 in K. Ganias, editor. Biology and Ecolgoy of Sardines and Anchovies, 1st edition. CRC Press, Boca Raton.

Gill, D. A., H. A. Oxenford, R. A. Turner, and P. W. Schuhmann. 2017. Making the most of data-poor fisheries: Low cost mapping of small island fisheries to inform policy. Marine Policy (April):0-1.

Gilmore, G.R. and Jones, R.S., 1992. Color variation and associated behavior in the epinepheline groupers, Mycteroperca microlepis (Goode and Bean) and M. phenax Jordan and Swain. Bulletin of Marine Science 51(1):83-103.

Glenn, H.D., Cowan, J.H. Jr, and J.E. Powers. 2017. A comparison of red snapper reproductive potential in the northwestern Gulf of Mexico: natural versus artificial habitats. Marine and Coastal Fisheries 9:139-148

Grüss, A., C. Biggs, W. D. Heyman, and B. Erisman. 2018. Prioritizing monitoring and conservation efforts for fish spawning aggregations in the U.S. Gulf of Mexico. Scientific Reports 8:1-10.

Grüss, A., C. R. Biggs, W. D. Heyman, and B. Erisman. 2019. Protecting juveniles, spawners or both: A practical statistical modelling approach for the design of marine protected areas. Journal of Applied Ecology 56(10): 2328-2339.

Grüss, A., and J. Robinson. 2014. Fish populations forming transient spawning aggregations: should spawners always be the targets of spatial protection efforts? ICES Journal of Marine Science 72(2):480-497.

Heyman, W. D., B. Kjerfve, R. T. Graham, K. L. Rhodes, and L. Garbutt. 2005. Spawning aggregations of Lutjanus cyanopterus (Cuvier) on the Belize Barrier Reef over a 6 year 
869

870

871

872

873

874

875

876

877

878

879

880

881

882

883

884

885

886

887

888

889

890

891

892

893

894

895

896

897

898

899

900

901

902

903

904

905

906

907

908

909

910

911

912

913

914

period. Journal of Fish Biology 67(1):83-101.

Heyman, W.D. and Kjerfve, B., 2008. Characterization of transient multi-species reef fish spawning aggregations at Gladden Spit, Belize. Bulletin of Marine Science, 83(3), pp.531551.

Heyman, W.D., Grüss, A., Biggs, C., Kobara, S., Farmer, N., Karnauskas, M., LowerreBarbieri, S., and B. Erisman. 2019. Cooperative monitoring, assessment, and management of fish spawning aggregations and associated fisheries in the U.S. Gulf of Mexico. Marine Policy 109: 103689.

Hilborn, R., and C. J. Walters. 1992. Quantitative fisheries stock assessment : choice, dynamics and uncertainty. Chapman and Hall, New York.

Hobday, A. J., A. D. M. Smith, I. C. Stobutzki, C. Bulman, R. Daley, J. M. Dambacher, R. A. Deng, J. Dowdney, M. Fuller, D. Furlani, S. P. Griffiths, D. Johnson, R. Kenyon, I. A. Knuckey, S. D. Ling, R. Pitcher, K. J. Sainsbury, M. Sporcic, T. Smith, C. Turnbull, T. I. Walker, S. E. Wayte, H. Webb, A. Williams, B. S. Wise, and S. Zhou. 2011. Ecological risk assessment for the effects of fishing. Fisheries Research 108:372-384.

Holt, S.A., 2008. Distribution of red drum spawning sites identified by a towed hydrophone array. Transactions of the American Fisheries Society, 137(2): 551-561.

Hordyk, A. R., and T. R. Carruthers. 2018. A quantitative evaluation of a qualitative risk assessment framework: Examining the assumptions and predictions of the Productivity Susceptibility Analysis (PSA). PLoS ONE 13(6):e0198298.

Jennings, S., J. D. Reynolds, and S. C. Mills. 1998. Life history correlates of responses to fisheries exploitation. Proceedings of the Royal Society B-Biological Sciences 265(1393):333-339.

Kindsvater, H. K., M. Mangel, J. D. Reynolds, and N. K. Dulvy. 2016. Ten principles from evolutionary ecology essential for effective marine conservation. Ecology and Evolution 6(7):2125-2138.

King, J. R., and G. McFarlane. 2003. Marine fish life history strategies: applications to fishery management. Fisheries Management \& Ecology 10:249-264.

Kobara S, Erisman B, Heyman W, Biggs C, Farmer N, Lowerre-Barbieri S, Karnauskas M, Brenner J. 2017. Cooperative monitoring program for spawning aggregations in the Gulf of Mexico: Data Portal Version 1.0. Available at: http://geo.gcoos.org:8010/restore/

Koenig, C.C., Coleman, F.C., Collins, L.A., Sadovy, Y., and P.L. Colin. 1996. Reproduction in gag (Mycteroperca microlepis) in the eastern Gulf of Mexico and the consequences of fishing spawning aggregations. In: Arregu, F., Munro, J.L., Balgos, M.C., and D. Pauly (eds) Biology, fisheries, and culture of tropical groupers and snappers: proceedings of an EPOMEX/ ICLARM International workshop on tropical snappers and groupers. Campeche, Mexico, 26-29 October 1993. ICLARM Conf Proc 48. WorldFish, 1996.

Koenig, C.C., Coleman, F.C. and Kingon, K., 2011. Pattern of recovery of the goliath grouper Epinephelus itajara population in the southeastern US. Bulletin of Marine Science, 87(4):891-911.

Koenig, C.C., Bueno, L.S., Coleman, F.C., Cusick, J.A., Ellis, R.D., Kingon, K., Locascio, J.V., Malinowski, C., Murie, D.J. and C.D. Stallings. 2017. Diel, lunar, and seasonal spawning patterns of the Atlantic goliath grouper, Epinephelus itajara, off Florida, United States. Bulletin of Marine Science 93(2):391-406.

Koenig, C.C., Coleman, F.C. and C.R. Malinowski. 2020. Atlantic Goliath Grouper of Florida: To Fish or Not to Fish. Fisheries 45(1): 20-32. 
915 Leslie, H. M., X. Basurto, M. Nenadovic, L. Sievanen, K. C. Cavanaugh, J. J. Cota-Nieto, B. E. 916 Erisman, E. Finkbeiner, G. Hinojosa-Arango, M. Moreno-Báez, S. Nagavarapu, S. M. W. 917 Reddy, A. Sánchez-Rodríguez, K. Siegel, J. J. Ulibarria-Valenzuela, A. Hudson Weaver, 918 and O. Aburto-Oropeza. 2015. Operationalizing the social-ecological systems framework to

919

920

921

922

923

924

925

926

927

928

929

930

931

932

933

934

935

936

937

938

939

940

941

942

943

944

945

946

947

948

949

950

951

952

953

954

955

956

957

958

959

960

Lindeman, K.C., Pugliese, R., Waugh, G.T. and Ault, J.S. 2000. Developmental patterns within a multispecies reef fishery: management applications for essential fish habitats and protected areas. Bulletin of Marine Science 66(3): 929-956.

López-Rocha, J. A., M. O. Albañez-Lucero, F. Arreguín-Sánchez, and J. A. de Anda-Montañez. 2009. Analysis of the spatial and seasonal variation in catchability of red grouper, Epinephelus morio (Valenciennes, 1828), in the Campeche Bank before overfishing (19731977). Revista de Biología Marina y Oceanografia 44(3):751-761.

López-Rocha, J. A., and F. Arreguín-Sánchez. 2013. Spatial dynamics of the red grouper Epinephelus morio (Pisces: Serranidae) on the Campeche Bank, Gulf of Mexico. Scientia Marina 77(2):313-322.

Lowerre-Barbieri, S., S. L. W. Burnsed, and J. W. Bickford. 2016. Assessing reproductive behavior important to fisheries management: a case study with Red Drum, Sciaenops ocellatus. Ecological Applications 26(4):979-995.

Lowerre-Barbieri, S., G. DeCelles, P. Pepin, I. A. Catalán, B. Muhling, B. Erisman, S. X. Cadrin, J. Alós, A. Ospina-Alvarez, M. M. Stachura, M. D. Tringali, S. W. Burnsed, and C. B. Paris. 2017. Reproductive resilience: a paradigm shift in understanding spawner-recruit systems in exploited marine fish. Fish and Fisheries 18(2):285-312.

Lowerre-Barbieri, S., K. Ganias, F. Saborido-Rey, F., H. Murua, and J. Hunter. 2011. Reproductive timing in marine fishes: variability, temporal scales, and methods. Marine and Coastal Fisheries: Dynamics. Management, and Ecosystem Science, 3:71-91.

Lowerre-Barbieri, S., N. Henderson, J. Llopiz, S. Walters, J. Bickford, and R. Muller. 2009. Defining a spawning population of spotted seatrout (Cynoscion nebulosus) over temporal, spatial, and demographic scales. Marine Ecology Progress Series 394:231-245.

Lowerre-Barbieri, S., L. Crabtree, T. Switzer, S. Walters Burnsed, \& C. Guenther. 2015. Assessing reproductive resilience: an example with South Atlantic red snapper Lutjanus campechanus. Marine Ecology Progress Series, 526, 125-141. doi:10.3354/meps11212

Lowerre-Barbieri, S., M. D. Tringali, C. P. Shea, S. Walters Burnsed, J. Bickford, M. Murphy, and C. Porch. 2019. Assessing red drum spawning aggregations and abundance in the Eastern Gulf of Mexico: a multidisciplinary approach. ICES Journal of Marine Science (75):516-529.

Lowerre-Barbieri, S., H. Menendez, J. Bickford, T. S. Switzer, L. Barbieri, and C. Koenig. 2020. Testing assumptions about sex change and spatial management in the protogynous gag grouper, Mycteroperca microlepis. Marine Ecology Progress Series 639:199-214.

Mamauag, S. S., P. M. Alino, R. J. S. Martinez, R. N. Muallil, M. V. A. Doctor, E. C. Dizon, R. C. Geronimo, F. M. Panga, and R. B. Cabral. 2013. A framework for vulnerability assessment of coastal fisheries ecosystems to climate change-Tool for understanding resilience of fisheries (VA-TURF). Fisheries Research 147:381-393.

Maunder, M. N., and R. B. Deriso. 2013. A stock-recruitment model for highly fecund species based on temporal and spatial extent of spawning. Fisheries Research 146:96-101.

Methot, R. D., and C. R. Wetzel. 2013. Stock synthesis: A biological and statistical framework for fish stock assessment and fishery management. Fisheries Research 142:86-99.

Peer] reviewing PDF | (2020:11:55081:1:0:NEW 8 Jun 2021) 
961

962

963

964

965

966

967

968

969

970

971

972

973

974

975

976

977

978

979

980

981

982

983

984

985

986

987

988

989

990

991

992

993

994

995

996

997

998

999

1000

1001

1002

1003

1004

1005

1006

Morato, T., W. W. L. Cheung, and T. J. Pitcher. 2006. Vulnerability of seamount fish to fishing: fuzzy analysis of life-history attributes. Journal of Fish Biology 68(1):209-221.

Mullon, C., P. Fréon, and P. Cury. 2005. The dynamics of collapse in world fisheries. Fish and Fisheries 6:111-120.

Musick, J. A. 1999. Criteria to Define Extinction Risk in Marine Fishes. The American Fisheries Society Initiative, Fisheries 24(12):6-14.

National Marine Fisheries Service (NMFS) 2018. Fisheries of the United States, 2017. U.S. Dept. of Commerce, NOAA Current Fishery Statistics No. 2017. U.S. Dept. of Commerce, NOAA Current Fishery Statistics No. 2017.

Nelson, M. D., C. C. Koenig, F. C. Coleman, and D. A. Mann. 2011. Sound production of red grouper Epinephelus morio on the west Florida shelf. Aquatic Biology 12(2):97-108.

Nemeth, R. S. 2012. Ecosystem aspects of species that aggregat to spawn. Pages 21-55 in Y. Sadovy and P. Colin, editors. Reef Fish Spawning Aggregations: Biology, Research and Management. Springer.

Patrick, W. S., P. Spencer, O. Ormseth, J. Cope, J. Field, D. Kobayashi, T. Gedamke, E. Cortés, K. Bigelow, W. Overholtz, J. Link, and P. Lawson. 2009. Use of productivity and susceptibility indices to determine the vulnerability of a stock: with example applications to six U.S. fisheries. NOAA Techical Memo p90.

Patrick W.S, P. Spencer, J. Link, J. Cope, J. Field, D. Kobayashi, P. Lawson, T. Gedamke, E. Cortés, O. Ormseth, K. Bigelow, W. Overholtz. 2010. Using productivity and susceptibility indices to assess the vulnerability of united states fish stocks to overfishing. Fishery Bulletin 108:305-322.

Patterson, W.F. III, J.H. Cowan Jr., G.R. Fitzhugh, and D.L. Nieland. 2007. Red snapper ecology and fisheries in the U.S. Gulf of Mexico. Am Fish Soc Symp 60

Pearson, J.C. 1928. Natural History and Conservation of Redfish and Other Commercial Sciaenids on the Texas Coast, Government Printing Office, Washington, DC, 1928, pp. 129-214.

Porch, C.E. 2000. Status of the red drum stocks of the Gulf of Mexico. Southeast Fisheries Science Center. Sustainable Fisheries Division Contributions: SFD-99/00-85.

Porch, C.E, Fitzhugh, G.R., Lang, E.T., Lyon, H.M., and B.C. 2015. Estimating the dependence of spawning frequency on size and age in Gulf of Mexico Red Snapper. Marine and Coastal Fisheries 7:233-245

Reynolds, J. D., S. Jennings, and N. K. Dulvy. 2001. Life histories of fishes and population responses to exploitation. Pages 147-169 in J. D. Reynolds, G. M. Mace, K. H. Redford, and J. G. Robinson, editors. Conservation of Exploited Species. Cambridge University Press, Cambridge University.Robinson, J. 2015. Understanding the Causes of Vulnerability to Fishing in Reef Fishes that Aggregate. Australian Research Council Centre of Excellence for Coral Reef Studies, James Cook University.

Robinson, J., and M. Samoilys. 2013. Evaluation of an indicator-based framework for assessing the vulnerability of reef fish populations to spawning aggregation fisheries. Pages 102-112 in J. Robinson J and M. Samoilys, editors. Reef Fish Spawning Aggregations in the Western Indian Ocean: Research for Management. WIOMSA/SIDA/SFA/CORDIO. WIOMSA Book Series 13.

Robinson, J. 2015. Understanding the Causes of Vulnerability to Fishing in Reef Fishes that Aggregate. Ph.D. Dissertation. Australian Research Council Centre of Excellence for Coral Reef Studies, James Cook University. 
1007 Robinson, J., N. A. J. Graham, J. E. Cinner, G. R. Almany, and P. Waldie. 2015. Fish and fisher

1008

1009

1010

1011

1012

1013

1014

1015

1016

1017

1018

1019

1020

1021

1022

1023

1024

1025

1026

1027

1028

1029

1030

1031

1032

1033

1034

1035

1036

1037

1038

1039

1040

1041

1042

1043

1044

1045

1046

1047

1048

1049

1050

1051

1052 multispecies spawning aggregation site. Coral Reefs 34:371-382.

Robinson, O. J., O. P. Jensen, M. M. Provost, S. Huang, N. H. Fefferman, A. Kebir, and J. L. Lockwood. 2017. Evaluating the impacts of fishing on sex-changing fish: a game-theoretic approach. ICES Journal of Marine Science 74(3):652-659.

Rose, G. A., and D. W. Kulka. 1999. Hyperaggregation of fish and fisheries: how catch-per-uniteffort increased as the northern cod (Gadus morhua) declined. Canadian Journal of Fisheries and Aquatic Sciences 56(S1): 118-127.

Rosenberg, A. A., and V. R. Restrepo. 1994. Uncertainty and risk evaluation in stock assessment advice for U.S. marine fisheries. Canadian Journal of Fisheries and Aquatic Sciences 51(12):2715-2720.

Saaty, R. W. 1987. The analytic heirarchy process - what it is and how it is used. Mathematical Modelling 9:3-5.

Sadovy De Mitcheson, Y., and B. E. Erisman. 2012. Fishery and biological implications of fishing spawning aggregations, and the social and economic importance of aggregating fishes. Pages 405-565 in Y. Sadovy De Mitcheson and P. L. Colin, editors. Reef Fish Spawning Aggregations: Biology, Research and Management. Springer.

Sagarese, S. R., J. F. Walter, J. J. Isely, M. D. Bryan, and N. Cummings. 2015. A comparison of data-rich versus data-limited methods in estimating overfishing limits. Page SEDAR 46DW-01. SEDAR, North Charleston, SC.

Salas, S., R. Chuenpagdee, J. C. Seijo, and A. Charles. 2007. Challenges in the assessment and management of small-scale fisheries in Latin America and the Caribbean. Fisheries Research 87(1):5-16.

Salthaug, A., and S. Aanes. 2003. Catchability and the spatial distribution of fishing vessels. Canadian Journal of Fisheries and Aquatic Sciences 60:259-268.

Saucier, M. H., and D. M. Baltz. 1993. Spawning site selection by spotted seatrout, Cynoscion nebulosus, and black drum, Pogonias cromis, in Louisiana. Environmental Biology of Fishes 36:257-272.

Schram, M. J., and M. A. Steele. 2020. Experimental evidence of resilience to size-selective harvesting in a protogynous hermaphroditic reef fish, Rhinogobiops nicholsii. Journal of Experimental Marine Biology and Ecology 525:151320.

SEDAR. 2014a. SEDAR 33 - Gulf of Mexico Greater Amberjack Stock Assessment Report. SEDAR, North Charleston SC. 499 pp. Available online at: http://sedarweb.org/sedar-33

SEDAR. 2014b. SEDAR 33 - Gulf of Mexico Gag Stock Assessment Report. SEDAR, North Charleston SC. 609 pp. Available online at: http://www.sefsc.noaa.gov/sedar/Sedar Workshops.jsp?WorkshopNum=33

SEDAR. 2016a. SEDAR 49 Gulf of Mexico Data-limited Species: red drum, lane snapper, wenchman, yellowmouth grouper, speckled hind, snowy grouper, almaco jack, lesser amberjack. North Charleston, SC.

SEDAR. 2016b. SEDAR 33 Update Report Gulf of Mexico Gag Grouper. SEDAR. North Charleston, South Carolina. 123 pp. Available at: http://sedarweb.org/docs/suar/GagUpdateAssessReport Final 0.pdf

SEDAR. 2018. SEDAR 52 - stock assessment report Gulf of Mexico red snapper. SEDAR, North Charleston, SC. 434 p.

Skjold, F., A. Eide, and O. Flaaten. 1996. Production functions of the Norwegian bottom trawl 
1053

1054

1055

1056

1057

1058

1059

1060

1061

1062

1063

1064

1065

1066

1067

1068

1069

1070

1071

1072

1073

1074

1075

1076

1077

1078

1079

1080

1081

1082 fisheries of cod in the Barents Sea. ICES C. M. 1996/P(3):1-14.

Solmundsson, J., H. Karlsson, and J. Palsson. 2003. Sexual differences in spawning behaviour and catchability of plaice (Pleuronectes platessa) west of Iceland. Fisheries Research 61(13):57-71.

South Atlantic Fisheries Management Council. 2017. Amendment 36 to the fishery management plan for the Snapper Grouper fishery fo the South Atlantic Region; Actions to implement special management zones in the South Atlantic. Available at: Stobutzki, I., M. Miller, and D. Brewer. 2001. Sustainability of fishery bycatch: A process for assessing highly diverse and numerous bycatch. Environmental Conservation 28(2):167-181.

Szedlmayer, S.T., and S.A. Bortone. 2019. Red Snapper Biology in a Changing World. New York, CRC Press. 306 pp.

Tinhan, T., B. Erisman, O. Aburto-Oropeza, A. Weaver, D. Vázquez-Arce, and C. G. Lowe. 2014. Residency and seasonal movements in Lutjanus argentiventris and Mycteroperca rosacea at Los Islotes Reserve, Gulf of California. Marine Ecology Progress Series 501:191-206.

Wall, C. C., B. T. Donahue, D. F. Naar, and D. A. Mann. 2011. Spatial and temporal variability of red grouper holes within Steamboat Lumps Marine Reserve, Gulf of Mexico. Marine Ecology Progress Series 431(1):243-254.

Walters, S., S. Lowerre-Barbieri, J. Bickford, and D. Mann. 2009. Using a passive acoustic survey to identify spotted seatrout spawning sites and associated habitat in Tampa Bay, Florida. Transactions of the American Fisheries Society 138:88-98.

Wilberg, M. J., J. T. Thorson, B. C. Linton, and J. Berkson. 2009. Incorporating time-varying catchability into population dynamic stock assessment models. Reviews in Fisheries Science 18(1):7-24.

Winemiller, K. O. 2005. Life history strategies, population regulation, and implications for fisheries management. Canadian Journal of Fisheries and Aquatic Sciences 62(4):872-885. 
1083 Table 1 Definitions of life history and spawning behavior parameters included in the analysis.

1084

1085

1086

1087

1088

1089

1090

1091

1092

1093

1094

1095

1096

1097

1098

1099

1100

1101

1102

1103

1104

1105

1106

1107

1108

1109

1110

1111

1112

1113

1114

1115

1116

1117

1118

1119

1120

1121

Table 2 Definitions and categories of the extrinsic vulnerability indicators used in the analysis.

Table 3 Spawning behavior and life history characteristics for the 28 species analyzed. Values are specific to the GOM and reflect the average $( \pm \mathrm{SE})$. Definitions of each characteristic are in Table 1. An annotated table with citations for each entry is available online (http://geo.gcoos.org/restore/)

Table 4 Spawning season of 28 species in the Gulf of Mexico, sorted by family. Grey indicates the extent of the spawning season; black indicates the peak spawning months.

Figure 1 Flow chart illustrating the process of calculating intrinsic and extrinsic vulnerability scores. Definitions for each of the indicators, the scales used, and the weighted vulnerabilities are in Table 1 and Table 2.

Figure 2 Visualization of correlation matrix of spawning behavior and life history parameters. Blue indicates positive correlation and red reflects negative correlation. The size of the circle reflects the value of Spearman's rank correlation coefficient and boxes without an " $x$ " are significant $(\alpha=0.05)$.

Figure 3 Biplot of PCA showing the first two principal components. The arrows show the relative loadings of each $\mathrm{PC}$ axis and the color of the species indicates the stock status. Historically overfished species (Atlantic Goliath Grouper, Nassau Grouper, Red Drum, Gag Grouper, and Red Grouper) have been labelled overfished in addition to those species that are currently designated as overfished.

Figure 4 Box plot of Principal Component (PC) scores by stock status. The horizontal line within the box represents the mean value and the box outlines the interquartile range (IQR). Whiskers indicate the highest and lowest value within $1.5 * \mathrm{IQR}$, values outside that range are outliers and are plotted as points. Overfished and not overfished on PC2 are significantly different $(\mathrm{t}=1.88, \mathrm{df}=13.4, \mathrm{p}=0.08)$. Statistical comparisons were only made between overfished and not overfished scores.

Figure 5 Distribution of the overall vulnerability index of the 28 species. The position of each species within each quadrant indicates their relative vulnerability from low to very high. 


\section{Figure 1}

Flow chart illustrating the process of calculating intrinsic and extrinsic vulnerability scores.

Definitions for each of the indicators, the scales used, and the weighted vulnerabilities are in Table 1 and Table 2. 

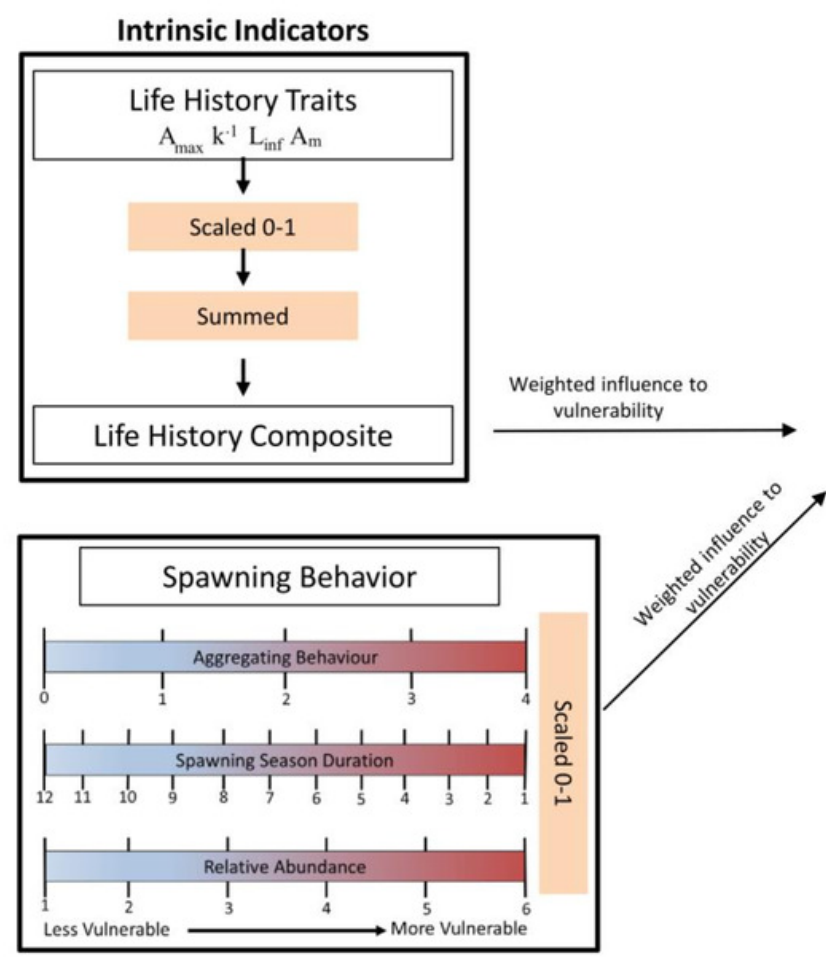
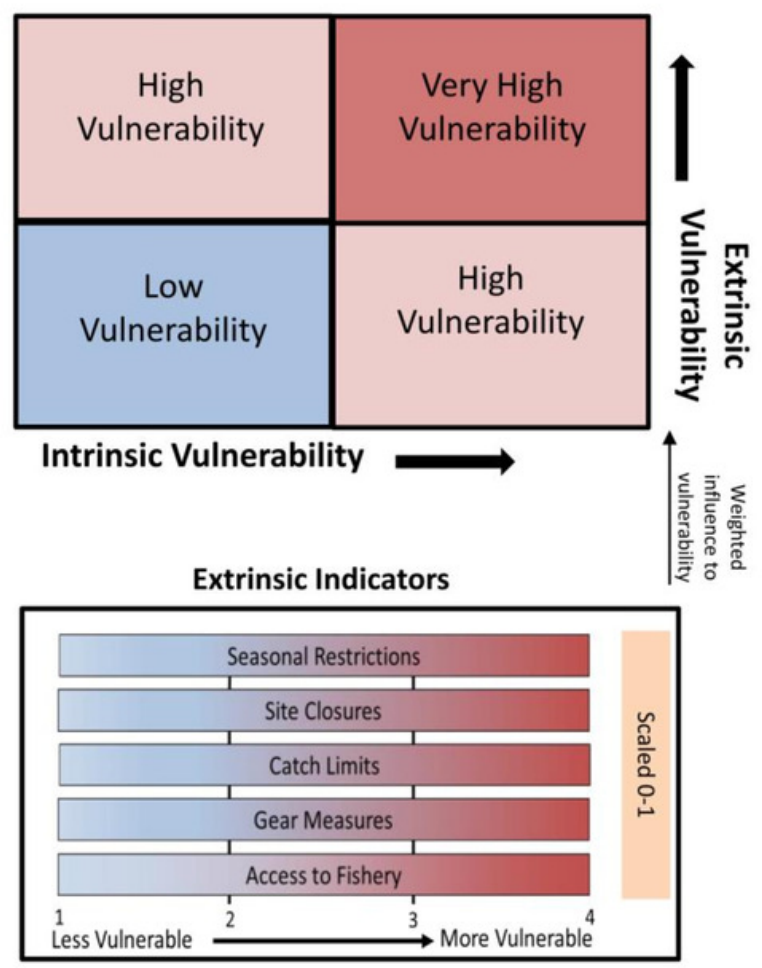
Figure 2

Visualization of correlation matrix of spawning behavior and life history parameters.

Blue indicates positive correlation and red reflects negative correlation. The size of the circle reflects the value of Spearman's rank correlation coefficient and boxes without an " $x$ " are significant $(\alpha=0.05)$. 


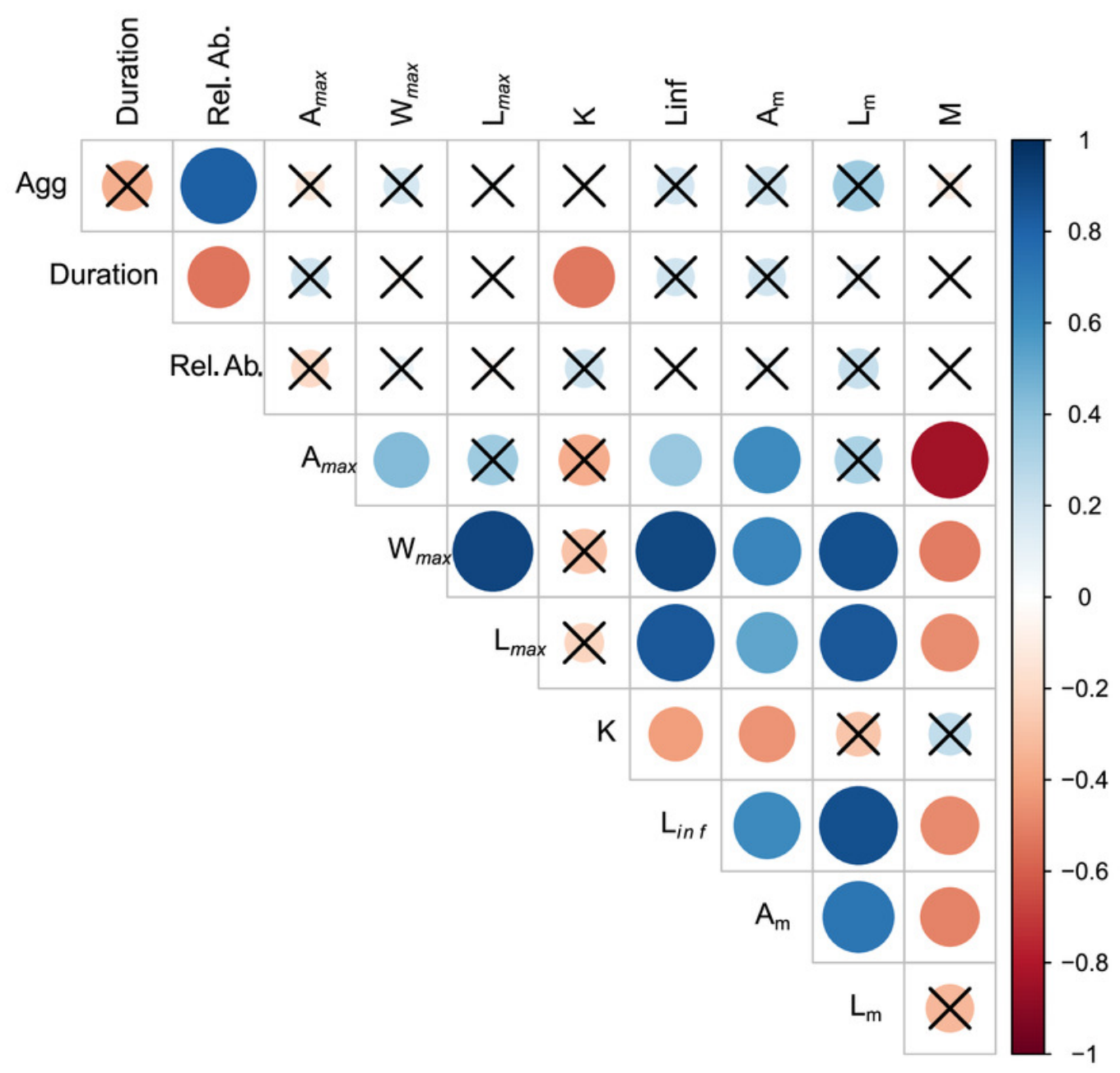




\section{Figure 3}

Biplot of PCA showing the first two principal components.

The arrows show the relative loadings of each PC axis and the color of the species indicates the stock status. Historically overfished species (Atlantic Goliath Grouper, Nassau Grouper, Red Drum, Gag Grouper, and Red Grouper) have been labelled overfished in addition to those species that are currently designated as overfished.

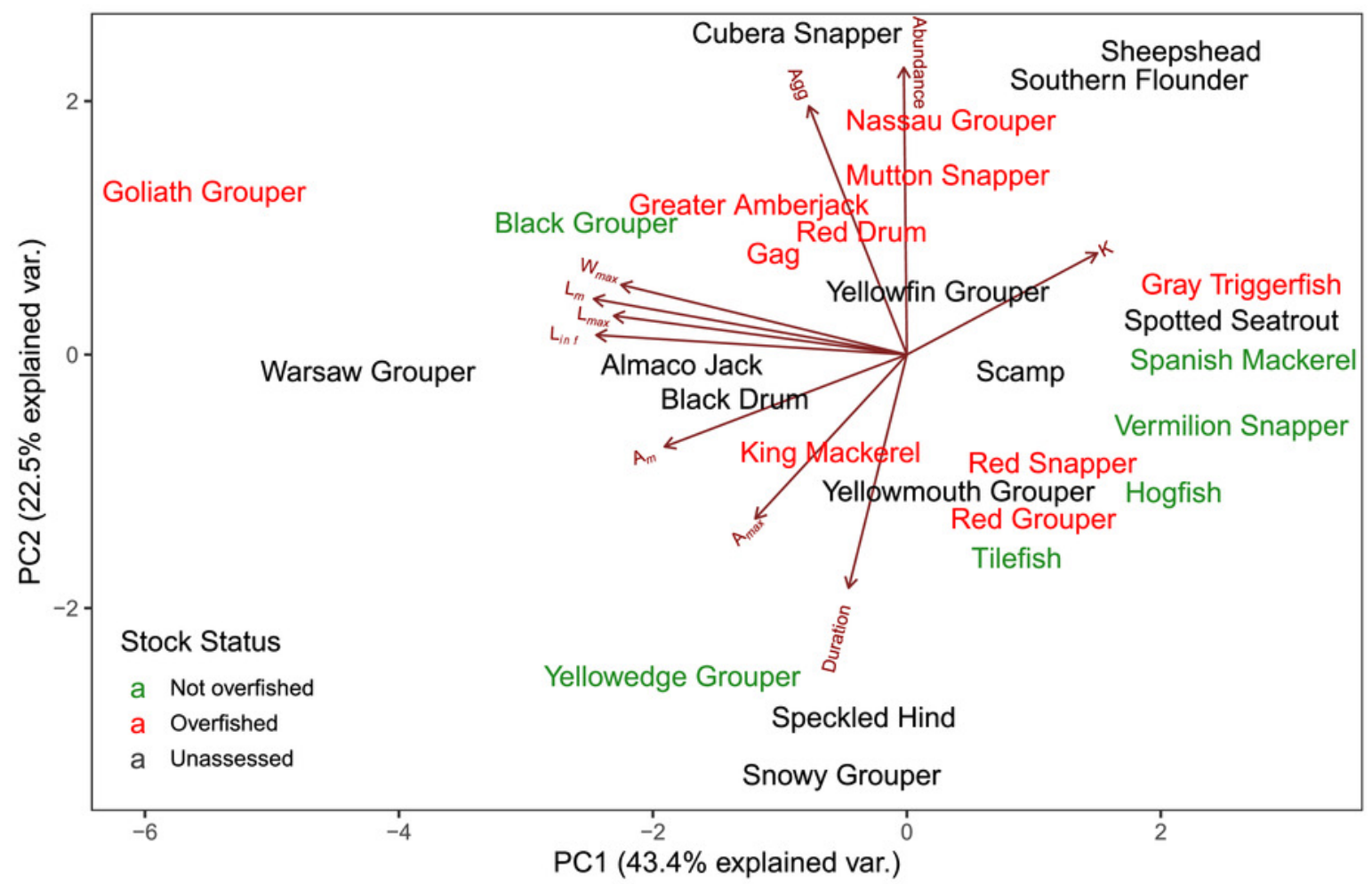




\section{Figure 4}

Box plot of Principal Component (PC) scores by stock status.

The horizontal line within the box represents the mean value and the box outlines the interquartile range (IQR). Whiskers indicate the highest and lowest value within $1.5 * I Q R$, values outside that range are outliers and are plotted as points. Overfished and not overfished on PC2 are significantly different $(t=1.88, d f=13.4, p=0.08)$. Statistical comparisons were only made between overfished and not overfished scores. 

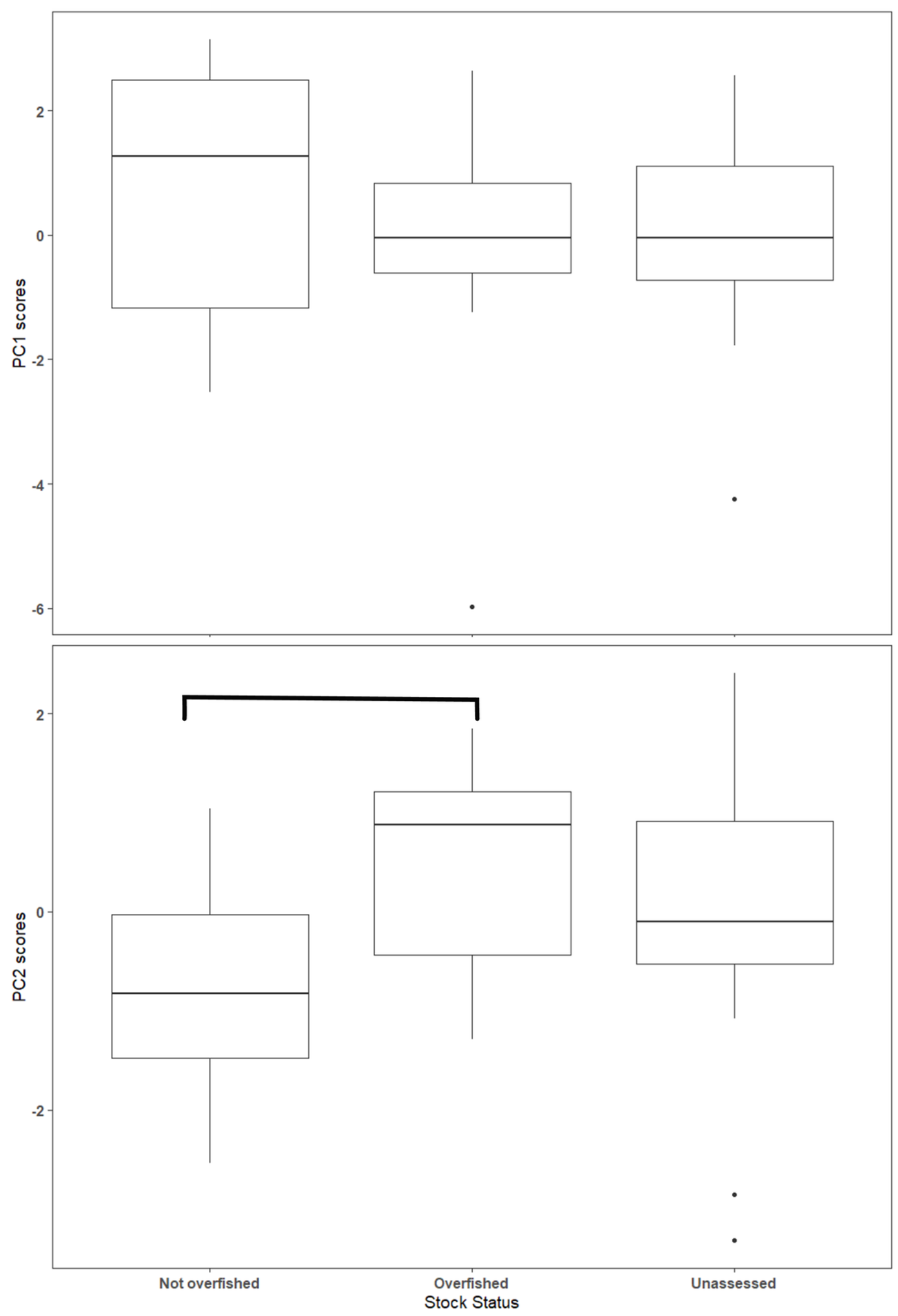

PeerJ reviewing PDF | (2020:11:55081:1:0:NEW 8 Jun 2021) 
Figure 5

Distribution of the overall vulnerability index of the 28 species.

The position of each species within each quadrant indicates their relative vulnerability from low to very high.

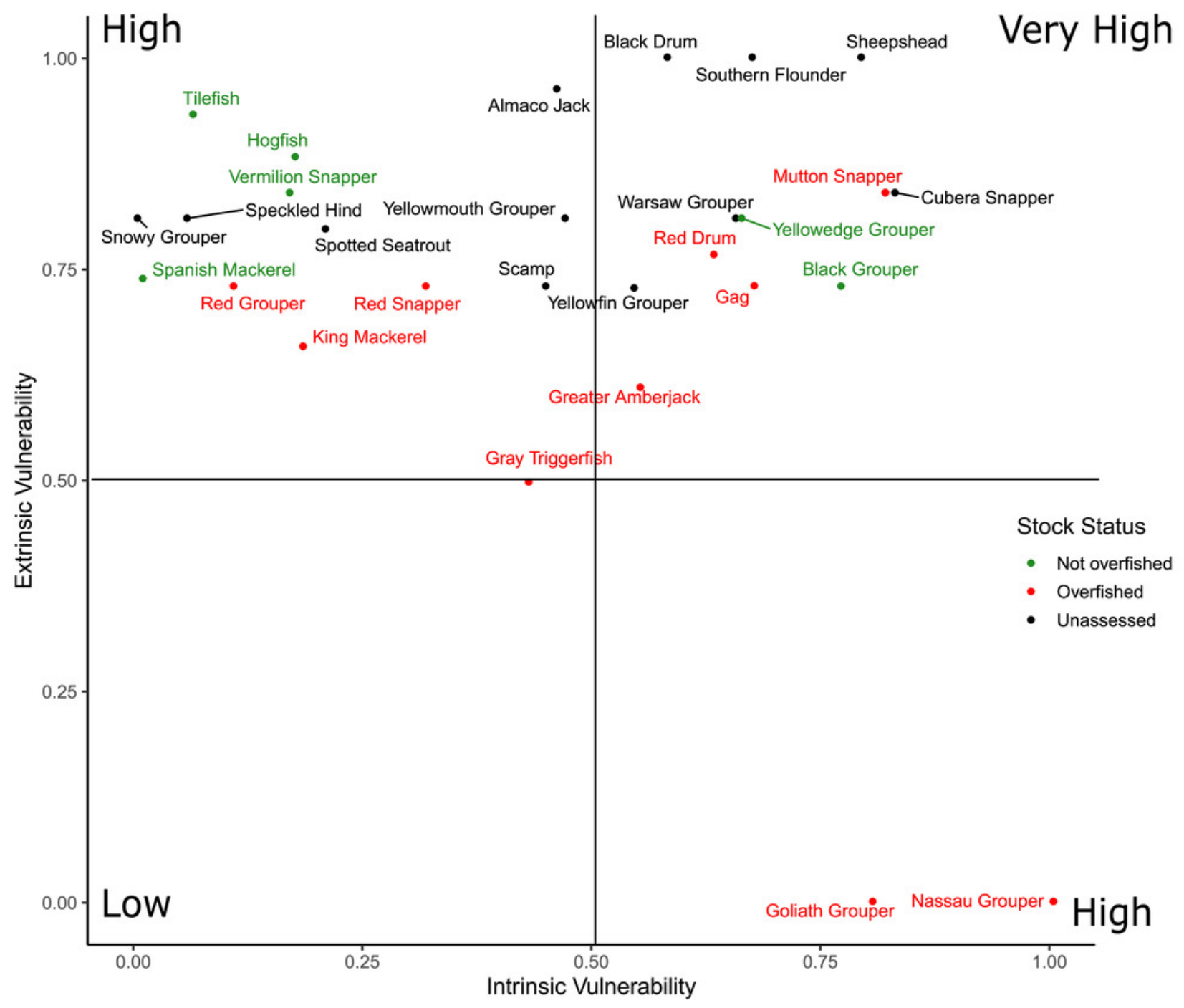




\section{Table 1 (on next page)}

Definitions of life history and spawning behavior parameters included in the analysis. 
1 Table 1 Definitions of life history and spawning behavior parameters included in the analysis.

\begin{tabular}{|c|c|c|c|c|}
\hline $\begin{array}{c}\text { Paramete } \\
\text { Type }\end{array}$ & Parameter & Abbreviation & $\begin{array}{c}\text { Weighted } \\
\text { influence on } \\
\text { vulnerability }\end{array}$ & Description \\
\hline \multirow[b]{3}{*}{$\begin{array}{l}\text { Spawning } \\
\text { Behavior }\end{array}$} & $\begin{array}{l}\text { Aggregating } \\
\text { Behavior }(0-4)\end{array}$ & Agg & 0.261 & $\begin{array}{l}\text { The degree of aggregating behavior associated with } \\
\text { spawning: does not aggregate }=0 \text {; simple migratory } \\
\text { spawner }=1 \text {; resident spawning aggregation }=2 ; \text { mixed } \\
\text { resident and transient aggregations }=3 \text {; transient } \\
\text { spawning aggregation }=4 \text {. }\end{array}$ \\
\hline & $\begin{array}{l}\text { Spawning } \\
\text { Season Duration } \\
\quad(1-12)\end{array}$ & Duration & 0.215 & $\begin{array}{l}\text { Number of months that the species spawns, with } \\
\text { shorter spawning seasons conferring higher } \\
\text { vulnerability to aggregation fishing. }\end{array}$ \\
\hline & $\begin{array}{c}\text { Relative } \\
\text { Abundance (1-6) }\end{array}$ & Rel. Ab. & 0.232 & $\begin{array}{l}\text { Change in abundance of fish relative to non- } \\
\text { reproductive periods. No change in abundance } \\
\text { between spawning and non-spawning periods }=1 \text {; } \\
\text { abundance doubles from solitary to few to ca. } 10 \text { fish } \\
\text { (clustering of polygynous groups) }=2 \text {; abundance } \\
\text { increases from small groups to } 100-200 \text { fish }=3 \text {; } \\
\text { abundance increases from small groups to } 500-1000 \\
\text { fish }=4 \text {; abundance increases from small groups to } \\
1,000-10,000 \text { fish }=5 \text {; abundance increases from small } \\
\text { groups to }>10,000 \text { fish }=6 \text {. Larger abundance changes } \\
\text { confer higher vulnerability to aggregation fishing. }\end{array}$ \\
\hline \multirow{8}{*}{$\begin{array}{c}\text { Life } \\
\text { History }\end{array}$} & Max Age (years) & $A_{\max }$ & \multirow{8}{*}{0.293} & Maximum age in years (longevity) \\
\hline & $\begin{array}{l}\text { Max Weight } \\
(\mathrm{kg})\end{array}$ & $W_{\max }$ & & Maximum weight in kilograms \\
\hline & $\begin{array}{l}\text { Max Length } \\
\quad(\mathrm{cm})\end{array}$ & $L_{\max }$ & & $\begin{array}{l}\text { Maximum reported length for the species in } \\
\text { centimeters }\end{array}$ \\
\hline & $\begin{array}{l}\text { k (vB Growth } \\
\text { Coefficient) }\end{array}$ & $k$ & & von Bertalanffy growth coefficient \\
\hline & $\begin{array}{l}\mathrm{L}_{\text {inf }}(\text { Asymptotic } \\
\text { Length, cm) }\end{array}$ & $L_{i n f}$ & & $\begin{array}{l}\text { Asymptotic length for von Bertalanffy growth } \\
\text { equation, expressed in centimeters }\end{array}$ \\
\hline & $\begin{array}{l}\text { Age at Maturity } \\
\text { (months) }\end{array}$ & $A_{m}$ & & Age at $50 \%$ maturity in months \\
\hline & $\begin{array}{c}\text { Length at } \\
\text { Maturity }(\mathrm{cm})\end{array}$ & $L_{m}$ & & Length at $50 \%$ maturity in centimeters \\
\hline & $\begin{array}{l}\text { M (Natural } \\
\text { Mortality) }\end{array}$ & $M$ & & Death rate per year not associated with fishing \\
\hline
\end{tabular}


Table 2 (on next page)

Definitions and categories of the extrinsic vulnerability indicators used in the analysis 
1 Table 2 Definitions and categories of the extrinsic vulnerability indicators used in the analysis.

2

\begin{tabular}{|c|c|c|}
\hline Parameter & $\begin{array}{l}\text { Weighted } \\
\text { influence on } \\
\text { vulnerability }\end{array}$ & Description \\
\hline Access to Fishery (1-4) & 0.081 & $\begin{array}{l}\text { Extent to which access to the fishery is limited. } 4=\text { open } \\
\text { (basic commercial/recreational license), } 3=\text { reef fish } \\
\text { permit (comm. regulation) and or charter/headboat reef } \\
\text { fish and coastal pelagics permit (rec. regulation), } 2=\text { reef } \\
\text { fish permit \& IFQ program, } 1=\text { closed }\end{array}$ \\
\hline Catch Limits (1-4) & 0.215 & $\begin{array}{l}\text { Number of catch limits, } 4=0-1 \text { regulation, } 3=2-3 \\
\text { regulations, } 2=4 \text { regulations, } 1=5 \text { regulations }\end{array}$ \\
\hline Gear Measures (1-4) & 0.114 & $\begin{array}{l}\text { Amount of restrictions on gear used, } 4=9 \text { or more } \\
\text { allowable gear types, } 3=6-8 \text { allowable gear types, } 2=3- \\
5 \text { allowable gear types, } 1=0-2 \text { allowable gear types }\end{array}$ \\
\hline $\begin{array}{l}\text { Seasonal Restrictions } \\
\qquad(1-4)\end{array}$ & 0.291 & $\begin{array}{l}\text { Spawning season prohibition of take or trade. } 4=\text { none, } \\
3=\text { seasonal closure, not during spawning, } 2=\text { seasonal } \\
\text { closure during peak spawning, } 1=\text { closed during entire } \\
\text { spawning season }\end{array}$ \\
\hline Site Closures (1-4) & 0.300 & $\begin{array}{l}\text { Spatial closure of spawning site. } 4=\text { no regulations, } 3= \\
\text { restricted gear, } 2=\text { site closed part of the year, } 1=\text { site } \\
\text { closed all year }\end{array}$ \\
\hline
\end{tabular}




\section{Table 3(on next page)}

Spawning behavior and life history characteristics for the 28 species analyzed.

Values are specific to the GOM and reflect the average $( \pm S E)$. Definitions of each characteristic are in Table 1. An annotated table with citations for each entry is available online (http://geo.gcoos.org/restore/) 
Table 3 Spawning behavior and life history characteristics for the 28 species analyzed. Values are specific to the GOM and reflect the average $( \pm \mathrm{SE})$ when multiple values were reported. Definitions of each characteristic are in Table 1. An annotated table with citations for each entry is available online (http://geo.gcoos.org/restore/)

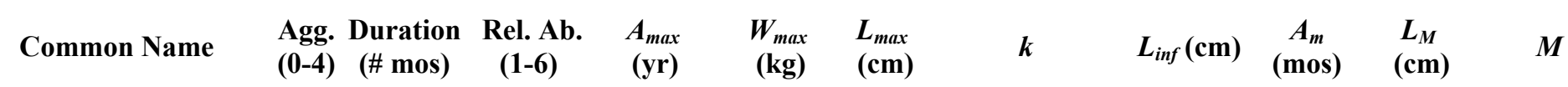

\begin{tabular}{lccccccccccc}
\hline \hline Gray Triggerfish & 2 & 4 & 4 & $15 \pm 1$ & 6 & 30 & $0.14 \pm 0.06$ & $59 \pm 3$ & $18 \pm 2$ & $17 \pm 3$ & 0.27 \\
Almaco Jack & 3 & 8 & 3 & 22 & 60 & 160 & 0.13 & 163 & 53 & 81 & $\mathrm{~N} / \mathrm{A}$ \\
Greater Amberjack & 3 & 4 & 3 & $15 \pm 1$ & 81 & 190 & $0.14 \pm 0.01$ & $144 \pm 7$ & $27 \pm 2$ & $79 \pm 4$ & $0.25 \pm 0.03$ \\
Black Grouper & 4 & 5 & 4 & $33 \pm 0$ & 163 & 150 & $0.14 \pm 0.01$ & $133 \pm 1$ & $78 \pm 4$ & $86 \pm 2$ & $0.14 \pm 0.02$ \\
Gag & 4 & 4 & 3 & $31 \pm 3$ & 37 & 145 & $0.13 \pm 0.01$ & $128 \pm 1$ & $42 \pm 2$ & $54 \pm 3$ & $0.13 \pm 0.01$ \\
Atlantic Goliath Grouper & 4 & 5 & 3 & $37 \pm 4$ & $363 \pm 68$ & 250 & $0.09 \pm 0.01$ & $222 \pm 6$ & $72 \pm 6$ & $120 \pm 3$ & $0.12 \pm 0.03$ \\
Nassau Grouper & 4 & 3 & 6 & $29 \pm 2$ & $27 \pm 0$ & 100 & $0.13 \pm 0.02$ & $76 \pm 3$ & $60 \pm 0$ & $40 \pm 2$ & $0.18 \pm 0.03$ \\
Red Grouper & 0 & 5 & 2 & $29 \pm 1$ & 23 & 125 & $0.13 \pm 0.02$ & $83 \pm 2$ & $34 \pm 6$ & $29 \pm 4$ & $0.14 \pm 0.02$ \\
Scamp & 3 & 6 & 3 & $31 \pm 1$ & 13 & 107 & $0.09 \pm 0.00$ & $77 \pm 9$ & $24 \pm 3$ & $33 \pm 1$ & $0.15 \pm 0.09$ \\
Warsaw Grouper & 3 & 8 & 3 & $41 \pm 0$ & $198 \pm 4$ & 235 & $0.05 \pm 0.00$ & $239 \pm 0$ & 49 & 81 & $\mathrm{~N} / \mathrm{A}$ \\
Yellowedge Grouper & 3 & 10 & 3 & $85 \pm 10$ & $20 \pm 1$ & 115 & $0.06 \pm 0.01$ & $100 \pm 3$ & $96 \pm 0$ & $55 \pm 9$ & $0.07 \pm .11$ \\
Yellowfin Grouper & 4 & 8 & 4 & $15 \pm 1$ & $19 \pm 0$ & 100 & $0.12 \pm 0.02$ & $89 \pm 6$ & 44 & $54 \pm 10$ & $0.26 \pm 0.05$ \\
Yellowmouth Grouper & 4 & 12 & 3 & $28 \pm 3$ & 9 & 84 & $0.08 \pm 0.01$ & $83 \pm 1$ & $36 \pm 11$ & $43 \pm 1$ & $0.23 \pm 0.02$ \\
Speckled Hind & 0 & 3 & 1 & $45 \pm 3$ & 30 & 110 & $0.12 \pm 0.01$ & $89 \pm 5$ & $79 \pm 9$ & $53 \pm 8$ & $0.15 \pm 0.01$ \\
Snowy Grouper & 0 & 10 & 1 & $35 \pm 2$ & 30 & 122 & $0.09 \pm 0.01$ & $106 \pm 5$ & $60 \pm 2$ & $60 \pm 4$ & $0.19 \pm 0.02$ \\
Hogfish & 2 & 8 & 2 & $23 \pm 1$ & $10 \pm 2$ & 91 & $0.11 \pm 0.08$ & $85 \pm 6$ & $11 \pm 2$ & $15 \pm 1$ & $0.18 \pm 0.11$ \\
Cubera Snapper & 4 & 4 & 6 & $22 \pm 1$ & $57 \pm 8$ & 160 & $0.16 \pm 0.01$ & $120 \pm 7$ & $24 \pm 9$ & $62 \pm 6$ & $0.15 \pm 0.08$ \\
Mutton Snapper & 4 & 4 & 5 & $40 \pm 6$ & $16 \pm 3$ & 94 & $0.17 \pm 0.01$ & $86 \pm 4$ & $48 \pm 3$ & $50 \pm 5$ & $0.11 \pm 0.03$ \\
Red Snapper & 2 & 5 & 2 & $48 \pm 4$ & $23 \pm 2$ & 100 & $0.19 \pm 0.05$ & $86 \pm 4$ & $24 \pm 3$ & $23 \pm 2$ & $0.1 \pm 0.02$ \\
Vermilion Snapper & 2 & 6 & 2 & $26 \pm 2$ & 3 & 63 & $0.33 \pm 0.04$ & $34 \pm 2$ & $24 \pm 4$ & $14 \pm 3$ & $0.25 \pm 0.03$ \\
& & & & & & & $0.13 \pm 0.01$ & & & \\
Tilefish & 0 & 6 & 2 & $40 \pm 3$ & 26 & 125 & & $93 \pm 3$ & $24 \pm 2$ & $34 \pm 5$ & $0.13 \pm 0.01$ \\
Southern Flounder & 4 & 4 & 5 & $8 \pm 1$ & 9 & 92 & $0.28 \pm 0.08$ & $65 \pm 6$ & $24 \pm 5$ & 40 & 0.36
\end{tabular}




$\begin{array}{lccccccccccc}\text { Black Drum } & 3 & 7 & 4 & 58 \pm 8 & 51 & 150 & 0.17 \pm 0.02 & 114 \pm 21 & 60 & 65 \pm 2 & 0.06 \pm 0.00 \\ \text { Red Drum } & 3 & 4 & 4 & 42 \pm 2 & 45 & 160 & 0.32 \pm 0.04 & 88 \pm 7 & 48 \pm 8 & 68 \pm 6 & 0.16 \pm 0.04 \\ \text { Spotted Seatrout } & 2 & 6 & 3 & 12 \pm 1 & 8 & 70 & 0.32 \pm 0.05 & 69 \pm 3 & 12 \pm 0 & 23 \pm 1 & 0.3 \\ \text { Gray Triggerfish } & 1 & 6 & 2 & 24 \pm 2 & 42 & 184 & 0.19 \pm 0.02 & 115 \pm 5 & 48 & 60 \pm 12 & 0.17 \pm 0.01 \\ \text { Almaco Jack } & 1 & 6 & 2 & 11 \pm 2 & 6 & 101 & 0.61 \pm 0.03 & 56 \pm 3 & 8 \pm 0.01 & 30 \pm 2 & 0.3 \\ \text { Greater Amberjack } & 4 & 3 & 5 & 20 \pm 2 & 10 & 92 & 0.36 \pm 0.03 & 46 \pm 1 & 24 \pm 6 & 30 & 0.15\end{array}$




\section{Table 4(on next page)}

Spawning season of 28 species in the Gulf of Mexico, sorted by family.

Grey indicates the extent of the spawning season; black indicates the peak spawning months. 
1 Table 4 Spawning season of 28 species in the Gulf of Mexico, sorted by family. Grey indicates

2 the extent of the spawning season; black indicates the peak spawning months.

Family

Common Name

Jan $\mid$ Feb Mar Apr|May Jun|Jul|Aug Sep|Oct|Nov|Dec

Epinephelidae

Epinephelidae

Black Grouper

Epinephelidae

Gag

Epinephelidae

Atlantic Goliath Grouper

Epinephelidae

Nassau Grouper

Epinephelidae Scamp

Epinephelidae Snowy Grouper

Epinephelidae Speckled Hind

Epinephelidae Warsaw Grouper

Epinephelidae Yellowedge Grouper

Epinephelidae Yellowfin Grouper

Epinephelidae Yellowmouth Grouper

Lutjanidae

Cubera Snapper

Lutjanidae

Mutton Snapper

Lutjanidae

Red Snapper

Lutjanidae

Vermilion Snapper

Sciaenidae

Black Drum

Sciaenidae

Red Drum

Sciaenidae

Spotted Seatrout

Scombridae

King Mackerel

Scombridae

Spanish Mackerel

Carangidae

Almaco Jack

Carangidae

Greater Amberjack

Sparidae

Sheepshead

Paralichthyidae Southern Flounder

Malacanthidae Tilefish

Labridae

Hogfish

Balistidae

Gray Triggerfish

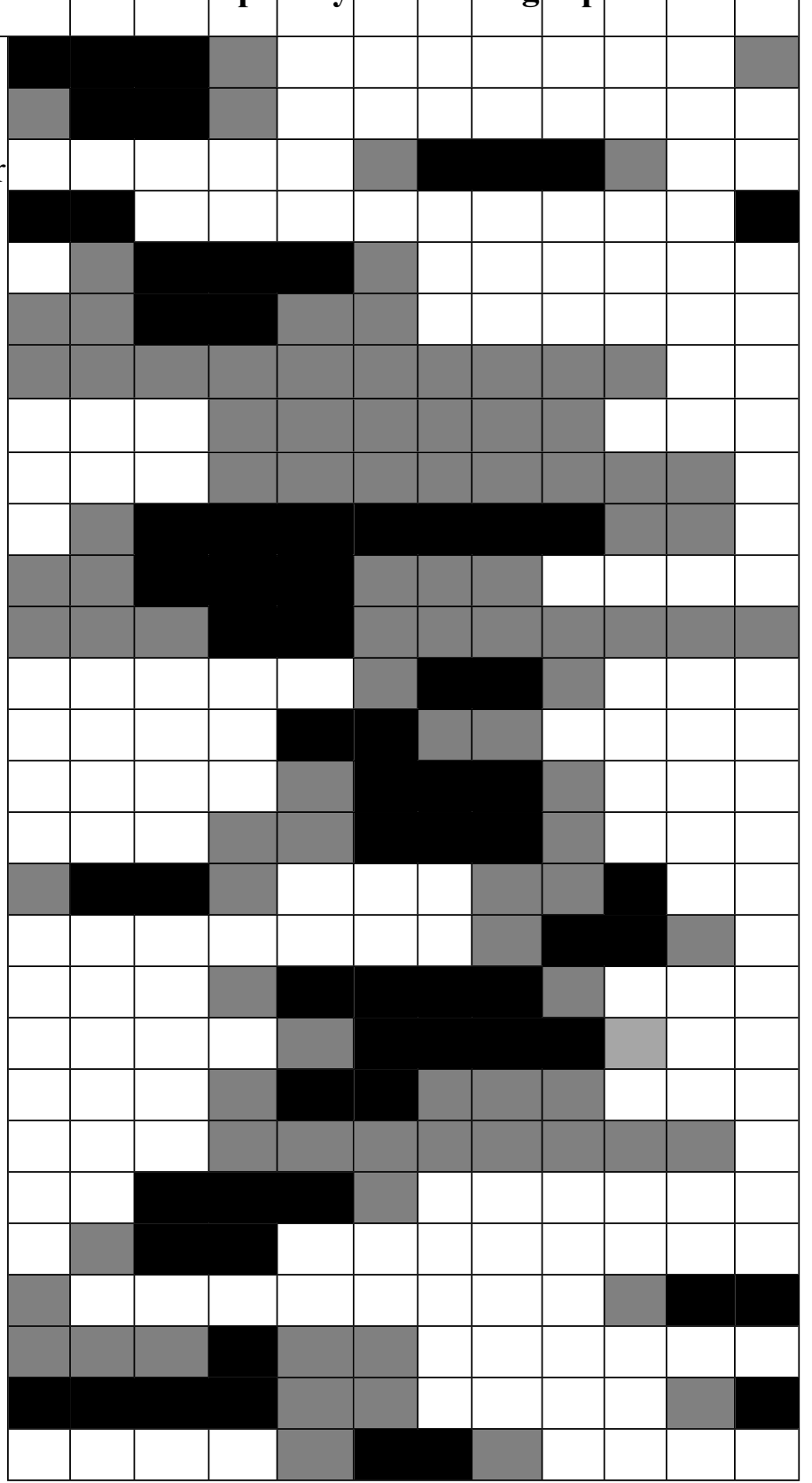

